Research Article

\title{
Study on the Mechanical Properties of Red Clay under Drying-Wetting Cycles
}

\author{
Yanli Qi $\mathbb{D}^{1}{ }^{1}$ MingZhou Bai ${ }^{(1)},{ }^{1,2}$ Hao Zhou, ${ }^{3}$ Hai Shi, ${ }^{1,2,4}$ Pengxiang Li, ${ }^{1}$ and Bohu He ${ }^{1}$ \\ ${ }^{1}$ Beijing Jiaotong University, School of Civil Engineering, Beijing 100044, China \\ ${ }^{2}$ Beijing Jiaotong University, Key Laboratory of Track Engineering, Beijing 100044, China \\ ${ }^{3}$ Shaoxing Traffic Engineering Management Center, Shaoxing 312000, China \\ ${ }^{4}$ Tsinghua University, State Key Laboratory of Hydro Science and Engineering, Beijing 100084, China \\ Correspondence should be addressed to MingZhou Bai; mzhbai@qq.com
}

Received 7 April 2021; Accepted 22 May 2021; Published 15 June 2021

Academic Editor: Robert Černý

Copyright ( 2021 Yanli Qi et al. This is an open access article distributed under the Creative Commons Attribution License, which permits unrestricted use, distribution, and reproduction in any medium, provided the original work is properly cited.

\begin{abstract}
To study the mechanical properties of red clay under repeated dry and wet cycle test conditions, in this paper, the disturbed red clay in an engineering area in Liuzhou, Guangxi Province, was taken as the research object. By artificially controlling different dry and wet cycles in the laboratory, a direct shear test and triaxial consolidation drainage test were carried out on the red clay samples after different dry and wet cycles. The stress-strain curve and change rule of corresponding $c$ and $\varphi$ values were obtained. The results showed that, in both the direct shear test and the triaxial test, the shear strength parameters of red clay decreased with an increase in the number of dry and wet cycles and the attenuation was most obvious during the first cycle. With an increase in the number of dry and wet cycles, the attenuation gradually decreased. The constitutive model of the deviatoric stress and strain curve of red clay under dry and wet cycles was a plastic-hardening type. By analyzing the variation in parameters in the P-H model, the relationship between $c, \varphi$, and the number of dry and wet cycles $n$ was obtained. The results showed that the parameters had different degrees of attenuation with the action of dry and wet cycles. To explain the above rules, some samples under different drying-wetting cycles were selected for environmental electron microscope scanning, and appropriate assumptions were made based on the microstructure.
\end{abstract}

\section{Introduction}

Red clay is a special clay with a high liquid limit, a high porosity ratio, a low compressibility, and other characteristics. It has poor engineering characteristics due to wet swelling, dry shrinkage, and easy-to-produce dry shrinkage cracks. Red clay is widely distributed in rainy areas in southern China. It is necessary to solve the engineering problems of red clay caused by rainfall and drying-wetting cycles during road engineering construction periods [1-3]. With the increase in infrastructure construction demand in the red-clay area of China, collapse and landslide of red clay slopes, subgrade cracking, and uneven settlement often occur. Therefore, it is of great significance to study the strength evolution law and microscopic mechanism of red clay under the action of drying-wetting cycles [4-6].
Many studies have been performed on the analysis of the soil strength evolution law. Yang et al. [7, 8], Kong et al. [9], Sun et al. [10], and Yang et al. [11] showed that although some physical properties of red clay and bentonite are similar, their mechanical properties are significantly different, so it is not possible to simply compare red clay with bentonite. Therefore, the study of red clay still needs to attract the attention of academics and engineers. Chen $[12,13]$ studied the shrinkage and strength characteristics of red clay by experimental means. Mu et al. [14] studied how the engineering properties of compacted red clay were affected by the number of wettingdrying cycles and the variation in moisture content in wetting-drying cycles by using consolidated drainage triaxial shear and compression tests.

Studies involving the analysis of microscopic mechanisms include the soil microscopic cement structure model 
proposed by Tan and Kong [15] nearly 20 years ago. This model basically explained the mechanism of some special engineering properties of red clay at that time. Tan et al. [16], to study the effect of compaction on the pore distribution of red clay, used the liquid nitrogen freeze-drying method to dry the compacted samples after removing the residual water content via a pressure plate apparatus; then, the authors tested the pore distribution characteristics with the pore apparatus. The results showed that conventional compaction can only change the pores in a certain range of large pore sizes but not pores with small pore sizes. This also indicated that the conventional compaction of red clay subgrade filler has a certain limit on the improvement of the compaction degree of soil.

Cheng et al. [3] adopted a direct shear test to carry out fast shear tests under saturated and dry states on red clay samples experiencing different cycles of drying and wetting to obtain their shear strength, analyze their strength index rules, and make assumptions of the microstructure model. Chen et al. [17] studied the variation of shear strength of alkali-contaminated unaltered red clay through an indoor fast shear test and used SEM scanning electron microscopy to explain the microscopic mechanism. This approach provided a foundation for the improvement of alkali-contaminated red clay and quantitative study of macroscopic microscopic mechanisms.

The above studies focused on the strength evolution law and micro mechanism analysis of red clay. At present, different red clays are selected for testing. Direct shear tests and triaxial tests are used to analyze the mechanical parameters of red clays separately, and the direct shear test is the main test method, while triaxial shear tests are rarely used. In addition, there are few studies involving the constitutive analysis of mechanical parameters and microstructure analysis of red clay.

Based on the above considerations, direct shear tests and triaxial consolidation and drainage tests were carried out on red clay after different wetting and drying cycles to obtain the stress-strain curves and the corresponding variation rules of $c$ and $\varphi$. Based on the variation rule of the shear strength index, the constitutive relation between $c, \varphi$, and the number of cycles $n$ is obtained by analyzing the parameter variation of the $\mathrm{P}-\mathrm{H}$ model. To explain the variation rule of the shear strength index of red clay, samples with different drying and wetting cycles were selected for environmental electron microscope scanning and quantitative statistical analysis using IPP (IPP, i.e., Image-Pro Plus, which is an image processing software), and a microstructure hypothesis was made for the variation rule of the strength of red clay.

\section{Experimental Scheme}

2.1. Basic Physical Parameters of Red Clay. The experimental soil was selected from the red clay slope of an expressway in Liuzhou city, Guangxi Province, China. According to the Standard for Geotechnical Test Methods (GB/T50123-1999) [18], the specific gravity, limit water content, particle composition, maximum dry density, and optimal water content of red clay were measured through experiments, and the basic physical properties and particle size composition of red clay were analyzed and obtained. The results are shown in Tables 1-2 and Figure 1.

In terms of physical properties and physical particle composition, the liquid plastic limit of red clay is relatively high. The liquid property index (IL) of red clay used in the experiment in this paper is 0.59 , within the range of $[0.25$, 0.75], indicating that it is plastic. According to the recommended value of the survey data, the natural density is $1.75 \mathrm{~g} / \mathrm{cm}^{3}$, natural pore ratio is 1.32 , natural water content is 44.87 , and specific gravity is 2.80 converted by the index. The specific gravity of red clay measured in the laboratory is 2.78 , which is slightly lower than the natural specific gravity. The reasons are as follows: (1) The error caused by the gas in the laboratory test soil is not completely eliminated, which makes the mass of water in the same body larger; and (2) the measured soil contains coarse and incompletely weathered rock particles, which makes the calculated value too high. According to the Engineering Geology Manual [19], the specific gravity of red clay is $2.76-2.90$, which indicates that the test value is relatively reliable.

According to the test results, particle size $d \leq 0.002 \mathrm{~mm}$ accounted for $41.5624 \%$, particle size $d$ within the range of $0.002-0.005 \mathrm{~mm}$ accounted for $11.7339 \%$, particle size $d$ within the range of $0.005-0.075 \mathrm{~mm}$ accounted for $38.7037 \%$, and particle size $d \geq 0.075 \mathrm{~mm}$ accounted for $8 \%$.

The results of compaction experiments show that the maximum dry density $\rho_{\mathrm{dmax}}$ is 1.485 and the optimal water content $w_{\text {opt }}$ is $28.3 \%$.

2.2. Sample Preparation. Based on the above basic physical parameters of red clay, 56 direct shear samples and 24 triaxial samples were prepared according to the test conditions shown in Tables 3 and 4 according to the Standard of Geotechnical Test Methods (GB/T50123-1999) [18]. The initial moisture content was $28.3 \%$, initial dry density was $1.26 \mathrm{~g} / \mathrm{cm}^{3}$, and a compacted soil sample with a diameter of $39.1 \mathrm{~mm}$ and a height of $80 \mathrm{~mm}$ was used in the triaxial test. The soil samples were filled in four layers, and each layer had a control height of $2 \mathrm{~mm}$. During the sample preparation process, a scraper was used to shave between the middle layers to ensure good contact of soil particles between layers.

Considering the particularity of direct shear samples, this direct shear test adopted the soaking time to simulate the drying-wetting cycle to investigate the influence of soaking time on the mechanical properties of soil, as shown in Figure 2. The experiment was carried out for $4 \mathrm{~h}, 8 \mathrm{~h}$, and $12 \mathrm{~h}$, with $1,2,3,5,7$, and 9 drying-wetting cycles and axial pressures of $50 \mathrm{kPa}, 100 \mathrm{kPa}, 200 \mathrm{kPa}$, and $300 \mathrm{kPa}$. The initial moisture content of the samples at the beginning of each test reached $28.3 \%$ and the moisture content of the samples was uniform. The experimental scheme is shown in Table 3.

In a triaxial consolidated drainage (CD) shear test, the vacuum saturation method was used to simulate the dryingwetting cycle, with $0,1,3,5,7$, and 9 drying-wetting cycles and axial pressures of $50 \mathrm{kPa}, 100 \mathrm{kPa}, 200 \mathrm{kPa}$, and $300 \mathrm{kPa}$. The experimental scheme is shown in Table 4. 
TABle 1: Physical properties of red clay for testing.

Density $\left(\mathrm{g} / \mathrm{cm}^{3}\right)$ Void ratio (e) The moisture content (\%) Proportion Plastic limit (\%) Liquid limit (\%) Plastic index (\%) Liquidity

$\begin{array}{llllllll} & & & & & \\ 1.75 & 1.32 & 44.87 & 2.804 & 29.613 & 55.418 & 25.805 & 0.59\end{array}$

TABLE 2: Composition of red clay particle size.

\begin{tabular}{lcccc}
\hline Particle size $d(\mathrm{~mm})$ & $\leq 0.002$ & $0.002-0.005$ & $0.005-0.075$ & $\geq 0.075$ \\
\hline Percentage $(\%)$ & 41.5624 & 11.7339 & 38.7037 & 8 \\
\hline
\end{tabular}

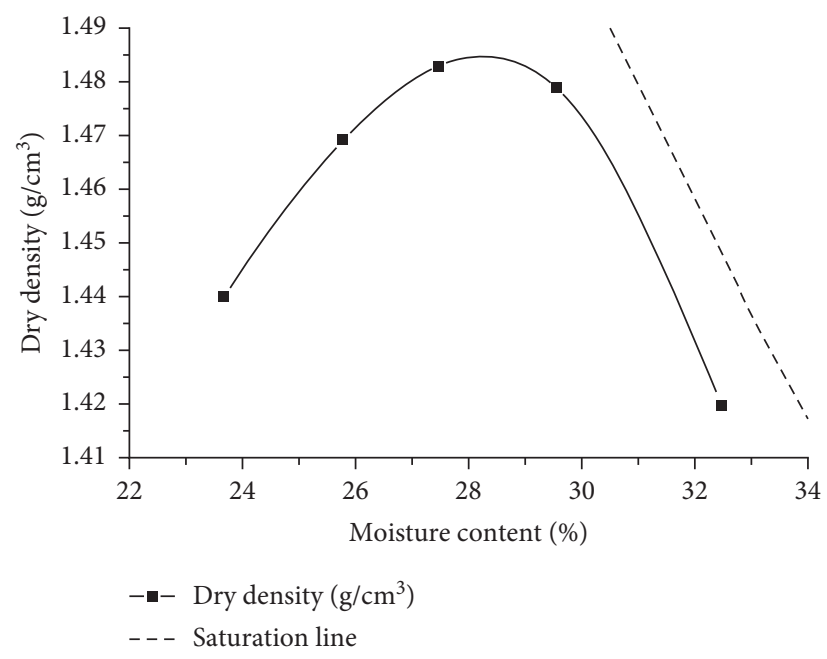

Figure 1: Compaction curve of red clay.

TABLE 3: Direct shear experimental scheme under dry and wet cycles.

\begin{tabular}{lccc}
\hline Initial moisture content $(\%)$ & Soaking time $t(\mathrm{~h})$ & Axial pressure $p(\mathrm{kPa})$ & Cycles $(\mathrm{n})$ \\
\hline & 4 & & $1,2,3,5,7,9$ \\
28.3 & 8 & $50,100,200,300$ & $1,3,5,7$ \\
& 12 & & $1,3,5,7$ \\
\hline
\end{tabular}

TABLE 4: CD experimental scheme.

\begin{tabular}{lcr}
\hline Initial dry density $\left(\mathrm{g} / \mathrm{cm}^{3}\right)$ & Confining pressure $p(\mathrm{kPa})$ & Cycles $(\mathrm{n})$ \\
\hline 1.26 & $50,100,200,300$ & $0,1,3,5,7,9$ \\
\hline
\end{tabular}

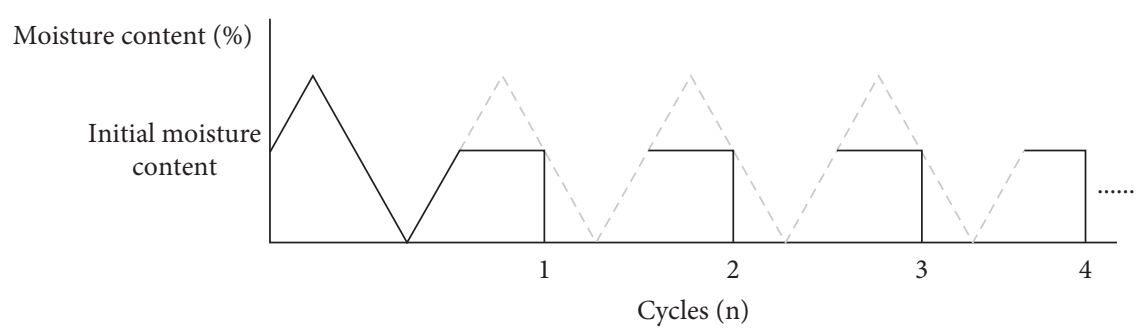

FIgURE 2: Schematic diagram of dry and wet cycles.

2.3. Experimental Methods. To study the influence of the wetting cycle (first wetting and then drying) on the mechanical properties of red clay, the humidification and drying method was implemented in a human laboratory. The specific implementation route is shown in Figure 3. 


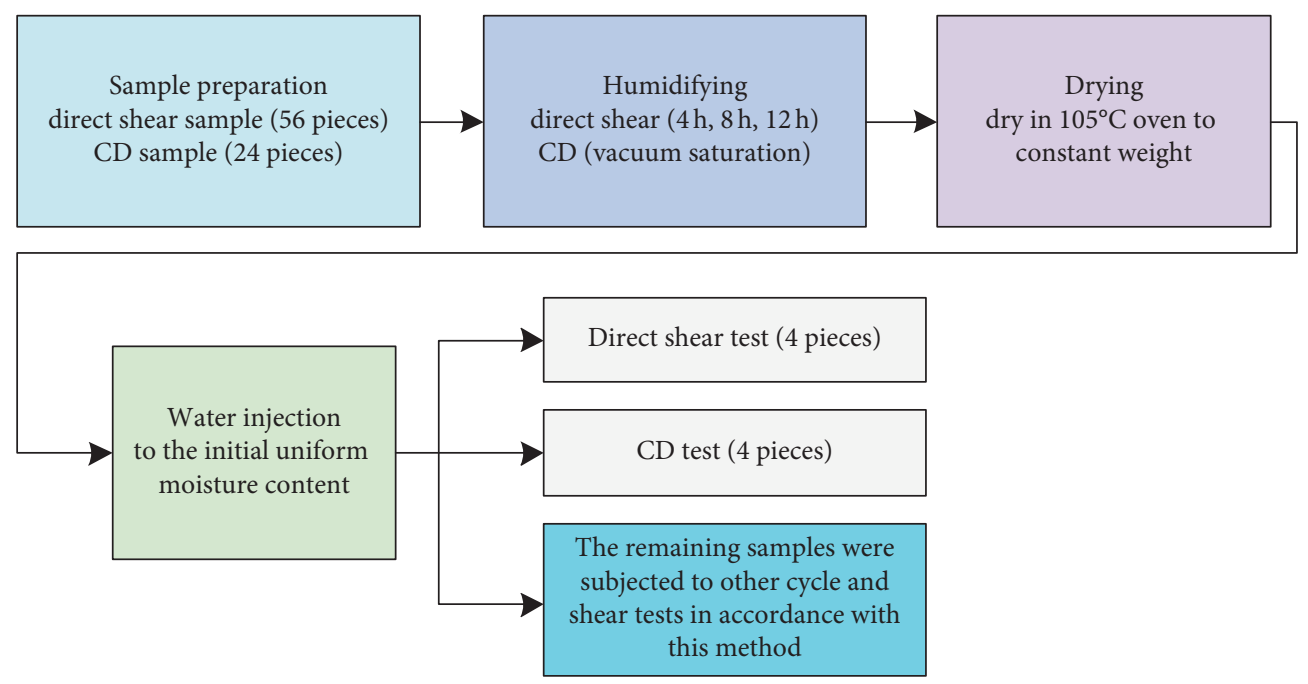

FiguRE 3: Implementation roadmap of a dry and wet cycle.

\section{Experimental Results and Analysis}

3.1. Analysis of Direct Shear Test Results. Through a direct shear test, the shear stress-shear displacement relationship curves of red clay with different wetting and drying cycles were obtained for $4 \mathrm{~h}$, as shown in Figure 4.

Figure 4 shows that the stress-strain curve of red clay shows plastic softening under low axial compression and plastic hardening with increasing axial compression. At the same time, the shear stress of red clay decreases with each drying and wetting action.

According to the test results, the failure strength curve of red clay under different cycles and the shear strength curve of red clay under different vertical pressures were drawn, as shown in Figure 5. The relationship curve of cohesion and internal friction angle with the number of drying-wetting cycles is shown in Figure 6.

As shown in Figure 5, the failure strength of red clay decreases with an increase in the number of wetting and drying cycles. The decrease is greater with an increase in wetting and drying cycles by $1-5$ times. At $300 \mathrm{kPa}$, the failure strength decreases to $33 \mathrm{kPa}$ after repeated drying and wetting. When the axial pressure is low, the failure strength attenuation is low. When the axial pressure is $50 \mathrm{kPa}$, the cumulative attenuation value is $11.5 \mathrm{kPa}$.

As shown in Figure 6, both the cohesion and internal friction angle decrease with an increase in the number of drying and wetting cycles, and both decrease greatly from the first $1-5$ cycles and gradually decrease with an increase in the number of cycles.

As above, the shear stress-shear displacement curves of wet and dry red clay for $8 \mathrm{~h}$ and $12 \mathrm{~h}$ were drawn, as shown in Figures 7 and 8.

As shown in Figures 7 and 8, with increasing soaking time, the shear curve features are similar. Most curves are plastically hardened, and a few are plastically softened. Linear fitting was performed for the shear strength in the experimental results, as shown in Figure 9.
The relationship curves of cohesion and internal friction angle with the number of drying-wetting cycles under the conditions of $8 \mathrm{~h}$ and $12 \mathrm{~h}$ of humidification were drawn, as shown in Figure 10.

As shown in Figure 10, the strength parameters of red clay have similar attenuation rules under different wetting conditions, and the influence of wetting time on strength attenuation is insignificant.

The shear strength parameters of red clay under different wetting conditions and different wetting and drying cycles were summarized in a direct shear test, as shown in Table 5. According to the parameters in Table 5, the curves of cohesion and internal friction angle of red clay changing with the number of drying-wetting cycles are shown in Figure 11.

As seen in Figure 11, under different wetting conditions, the attenuation law of cohesion and internal friction angle of red clay are similar, and both decrease with an increase in the number of drying and wetting cycles. The influence of wetting time on strength attenuation is insignificant.

3.2. Analysis of Triaxial (CD) Test Results. Consolidation and drainage test data of 24 samples in 6 groups were obtained by triaxial testing. The relation curve between the deviatoric stress and axial strain was obtained after processing the test data, as shown in Figure 12.

As shown in Figure 12, the triaxial compression curves of saturated red clay are all the plastic-hardening type with nonlinear, elastoplastic, and nondilatancy characteristics. In addition, according to the failure modes of the samples, the middle bulging features of all the samples did not exhibit shear failure surfaces.

Figure 13 plots the deviatoric stress curve under the same confining pressure. It can be seen from the figure that, under the same confining pressure, the deviatoric stress of red clay decreases with an increase in the number of cycles. The first cycle attenuated the deviatoric stress most obviously, and the attenuation gradually weakened with an increase in the number of cycles. When the confining pressure was $50 \mathrm{kPa}$, 


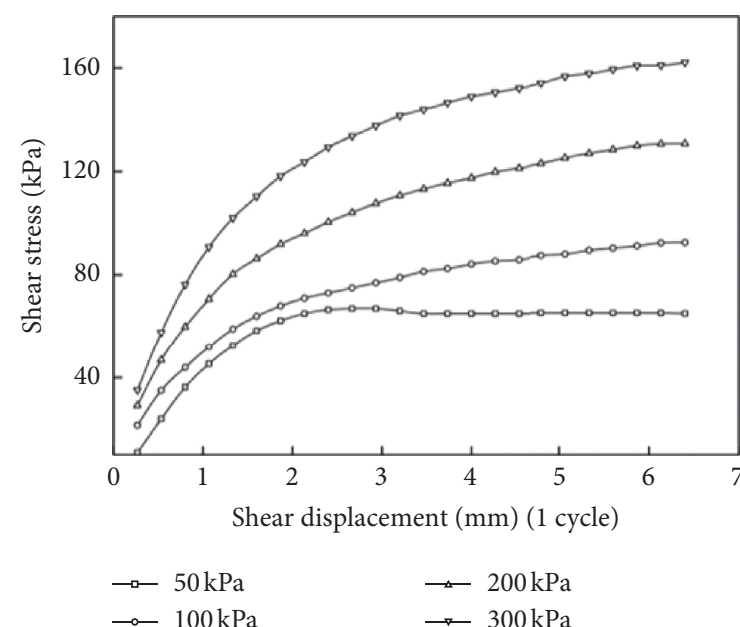

(a)

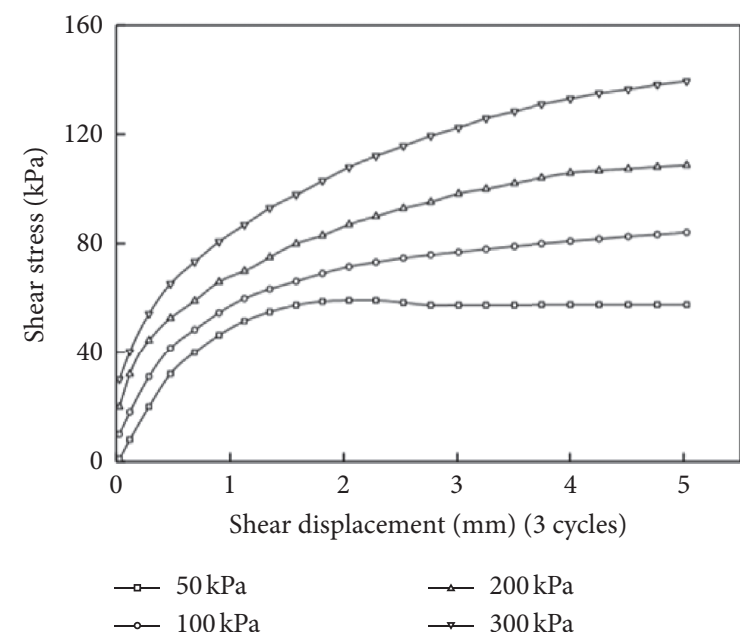

(c)

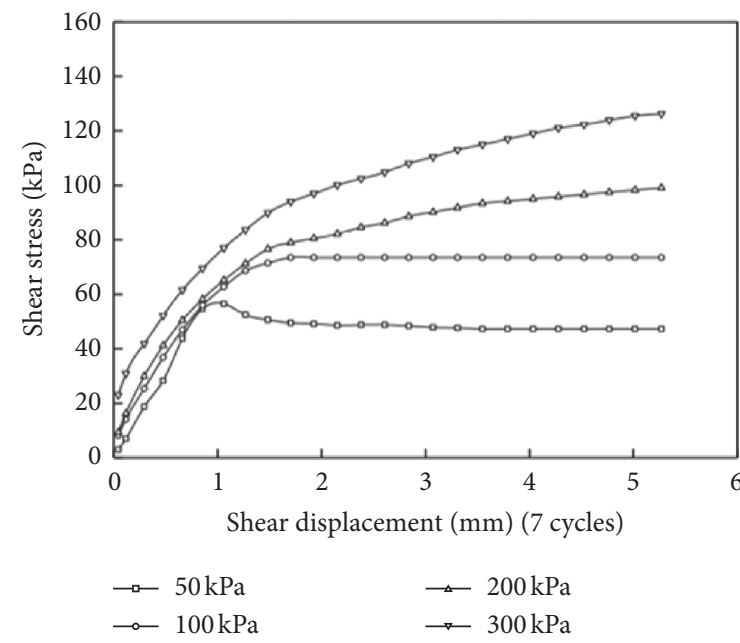

(e)

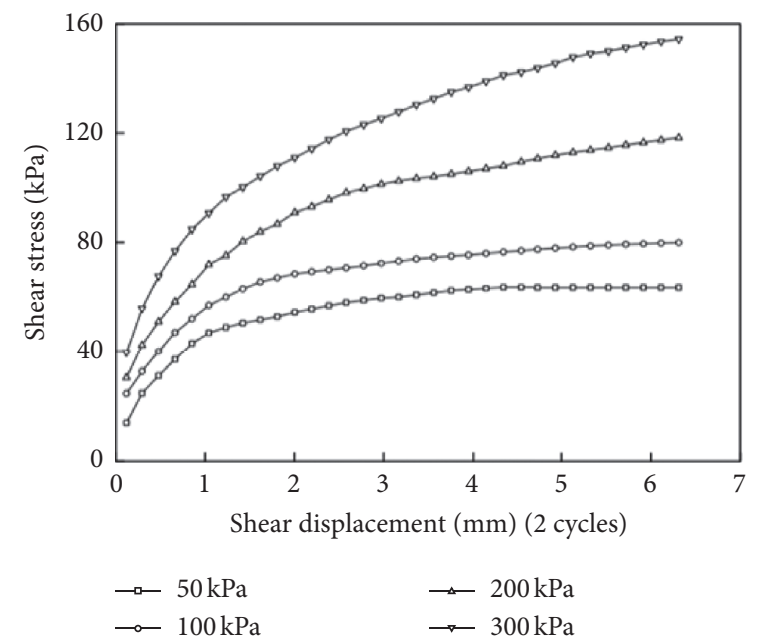

(b)

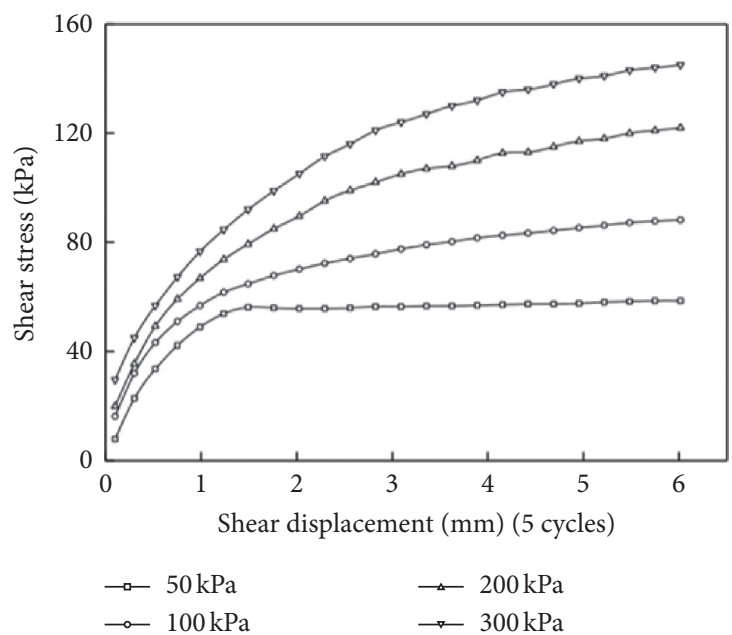

(d)

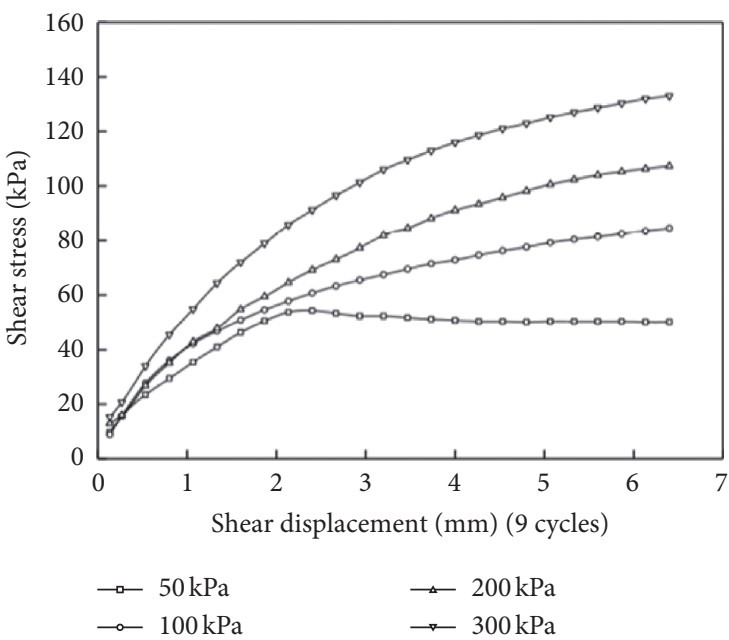

(f)

Figure 4: Straight shear test curve of red clay under different dry and wet cycles $\left(\rho_{\mathrm{d}}=1.26 \mathrm{~g} / \mathrm{cm}^{3}, \omega=28.3 \%\right.$, and $\left.t=4 \mathrm{~h}\right)$.

the deviatoric stress of red clay was $159.3603 \mathrm{kPa}$ and the minimum was $115.8213 \mathrm{kPa}$. The maximum deviatoric stress of red clay was $258.1136 \mathrm{kPa}$, and the minimum deviatoric stress was $193.8434 \mathrm{kPa}$ at a $100 \mathrm{kPa}$ confining pressure. The maximum deviatoric stress was $457.958 \mathrm{kPa}$, and the minimum deviatoric stress was $338.1566 \mathrm{kPa}$ under a $200 \mathrm{kPa}$ 


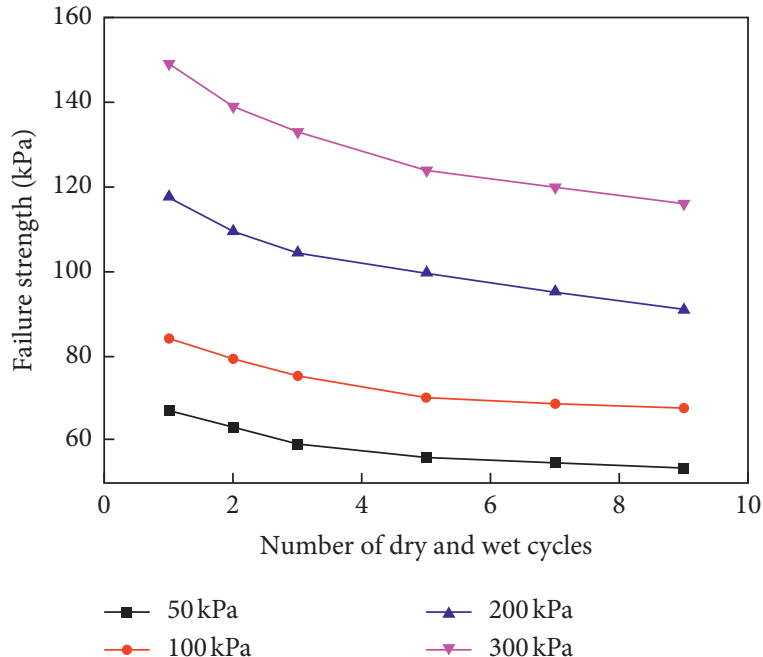

(a)

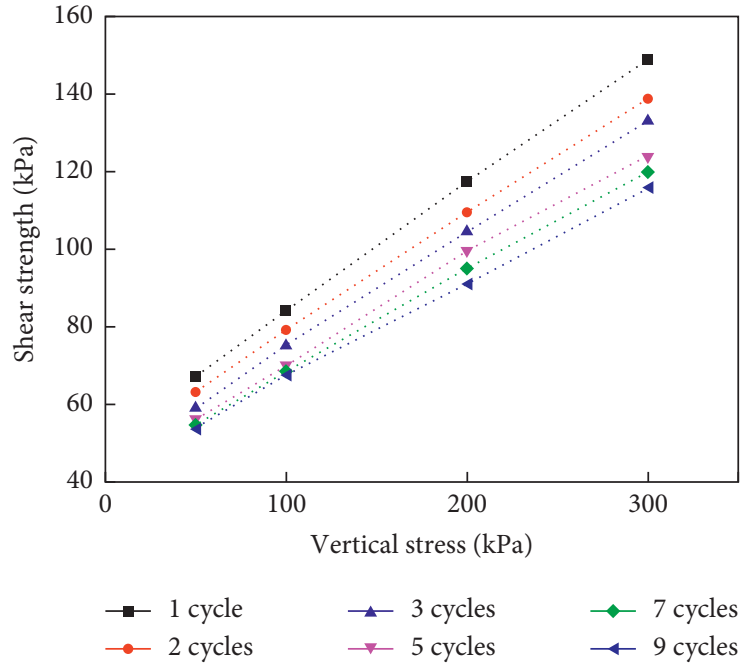

(b)

FIgURE 5: Failure strength curve and shear strength line of red clay under different dry and wet cycles (wet for $4 \mathrm{~h}$ ).

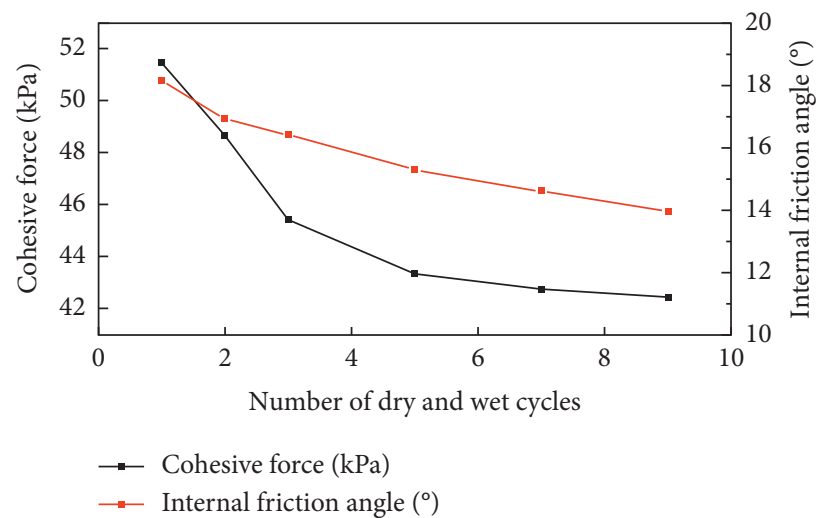

FiguRE 6: Shear strength parameters of red clay under different dry and wet cycles (wet for $4 \mathrm{~h}$ ).
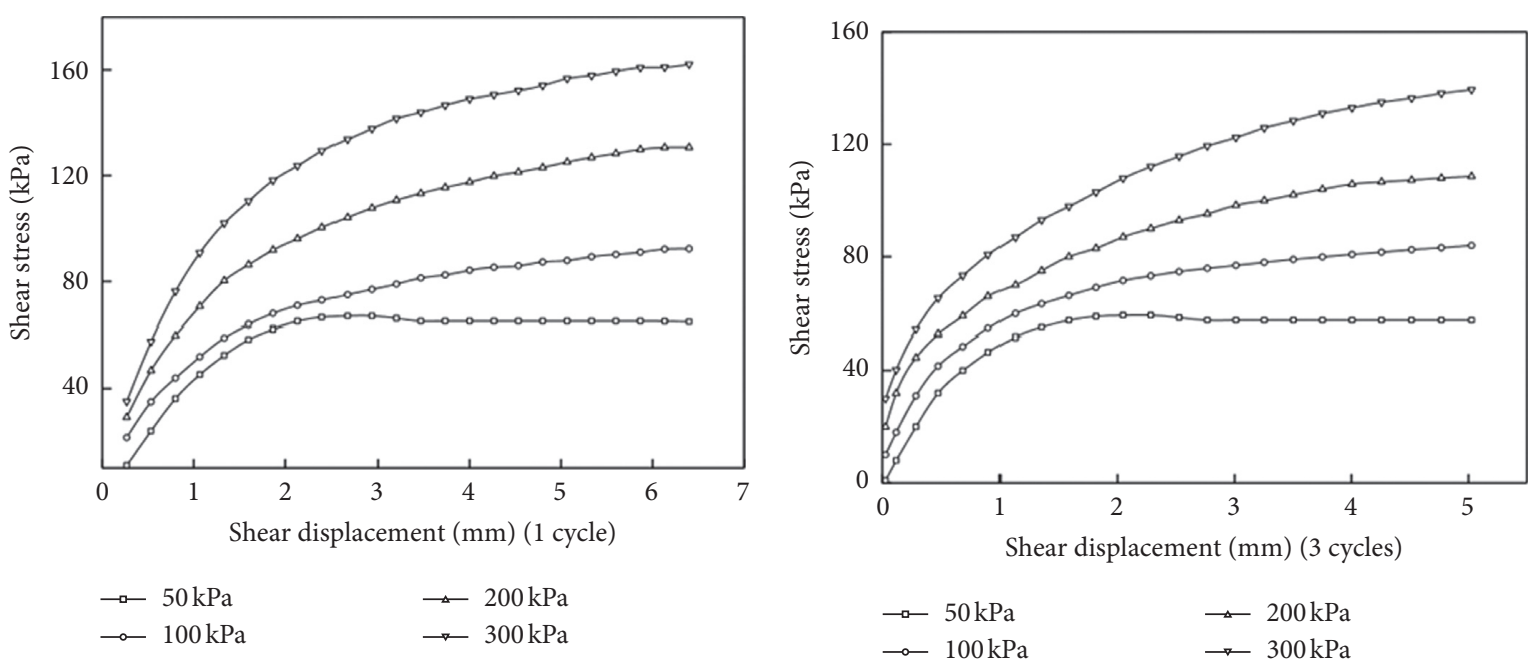

(a)

(b)

Figure 7: Continued. 


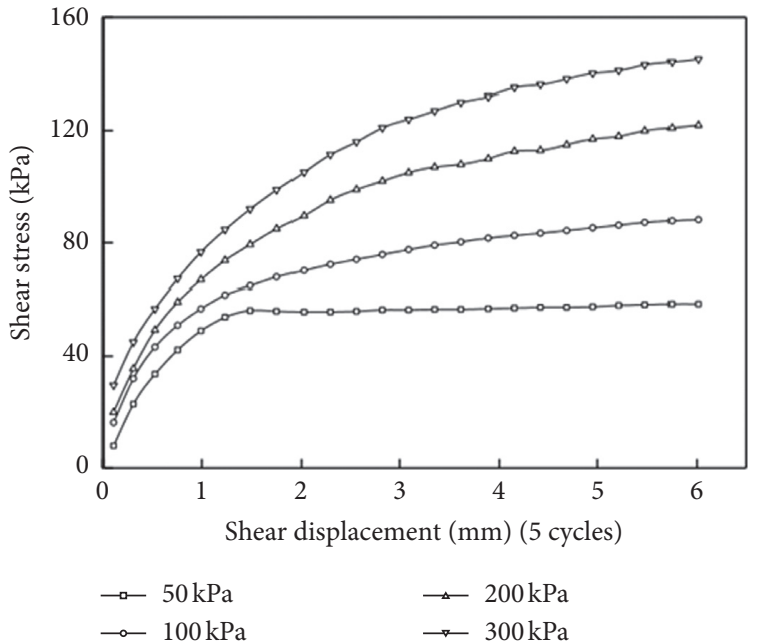

(c)

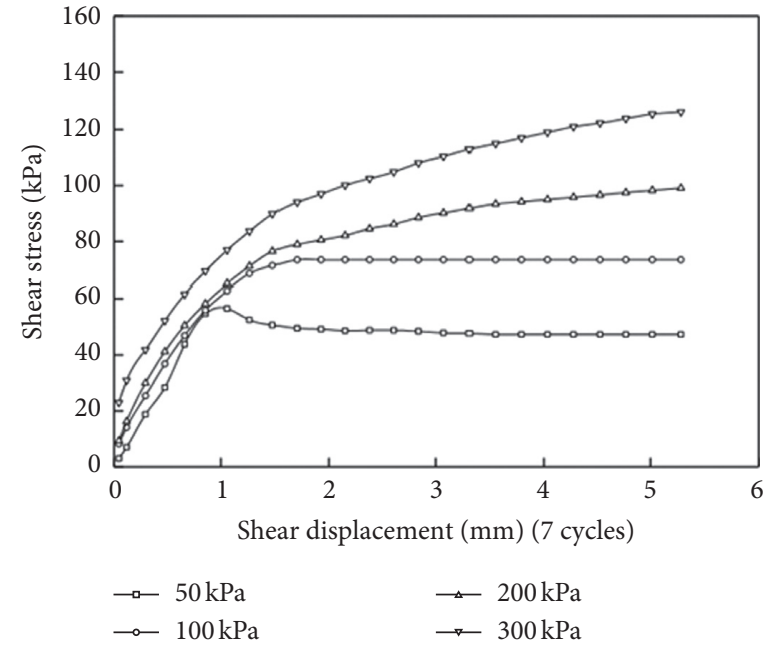

(d)

FIGURE 7: Straight shear test curve of red clay under different dry and wet cycles $\left(\rho_{\mathrm{d}}=1.26 \mathrm{~g} / \mathrm{cm}^{3}, \omega=28.3 \%\right.$, and $\left.t=8 \mathrm{~h}\right)$.
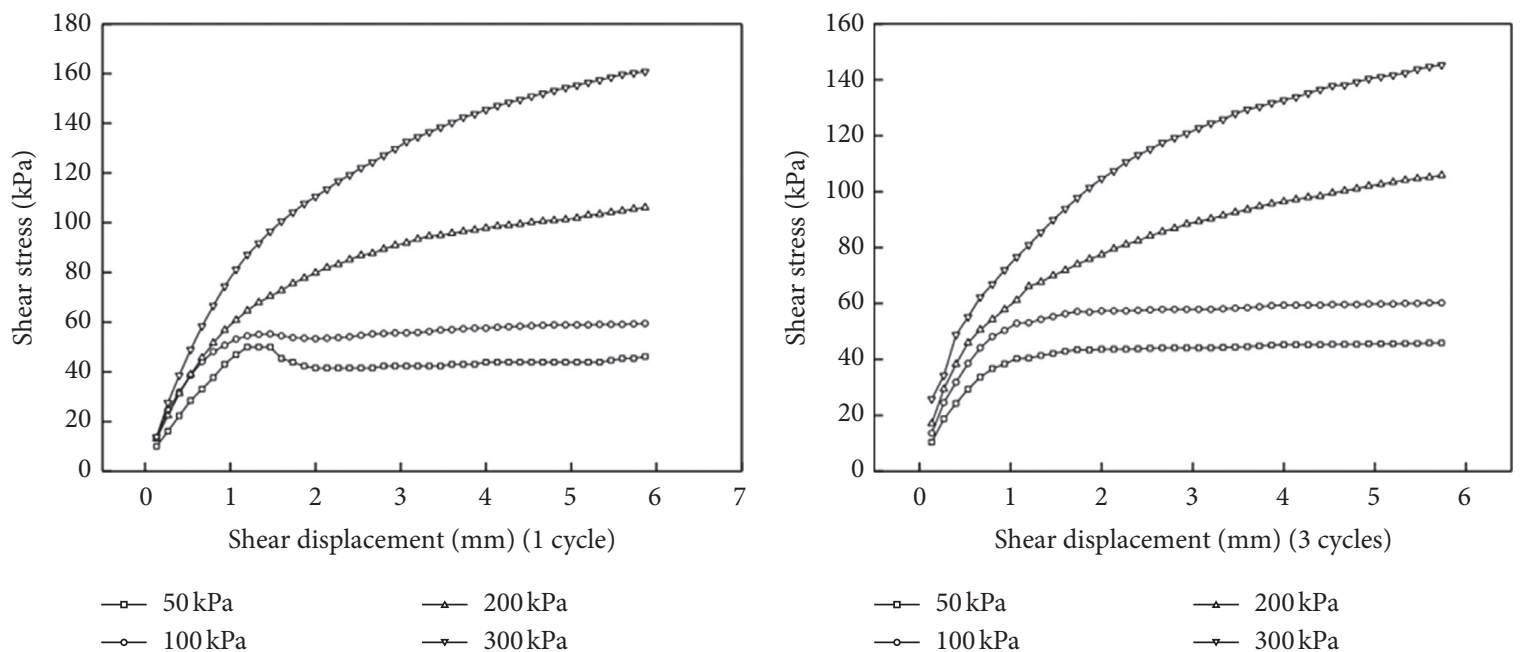

(a)

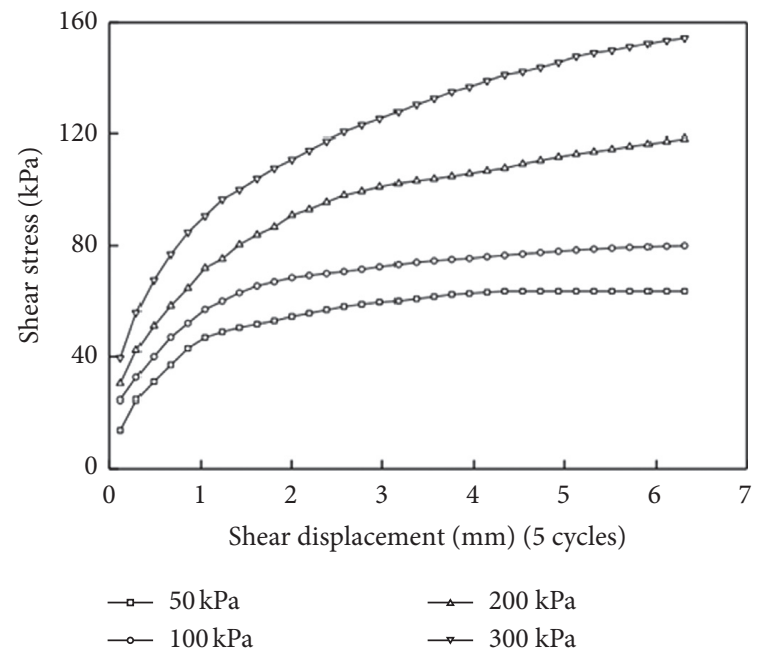

(c)

(b)

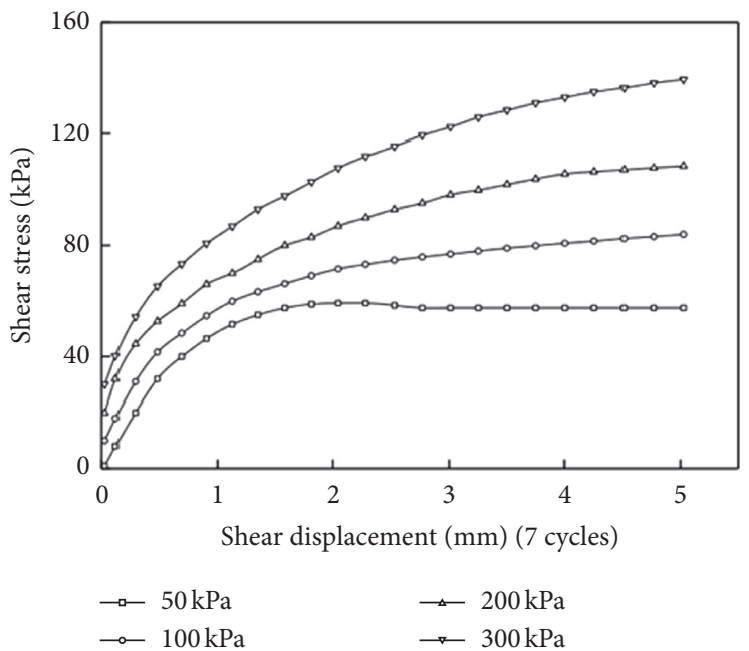

(d)

Figure 8: Direct shear test curve of red clay under different dry and wet cycles $\left(\rho_{\mathrm{d}}=1.26 \mathrm{~g} / \mathrm{cm}^{3}, \omega=28.3 \%\right.$, and $\left.t=12 \mathrm{~h}\right)$. 


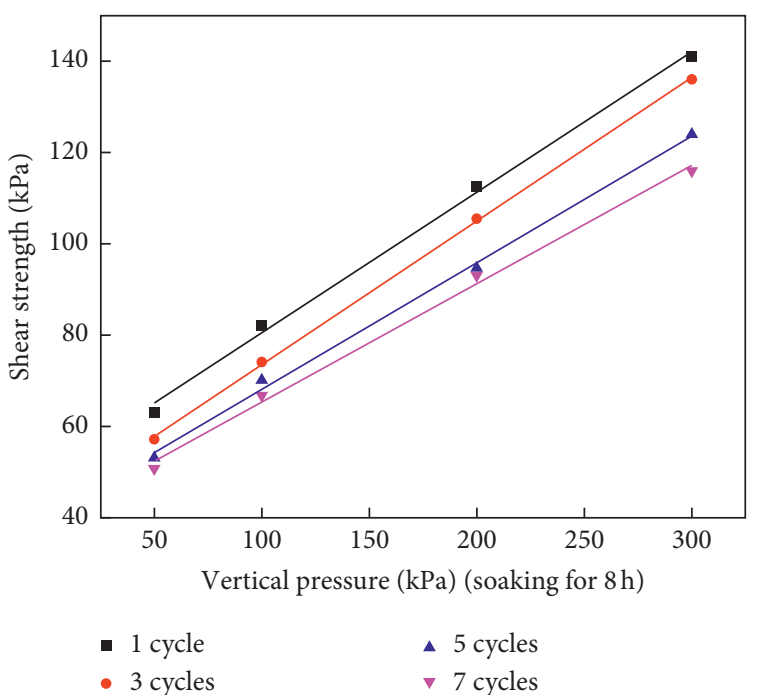

(a)

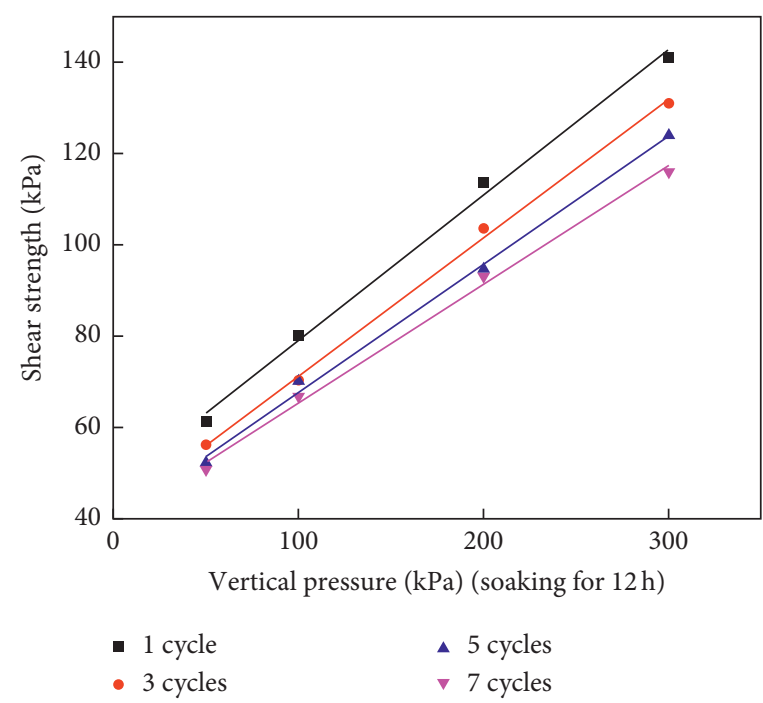

(b)

Figure 9: Results of direct shear test fitting ( $8 \mathrm{~h}$ and $12 \mathrm{~h})$.

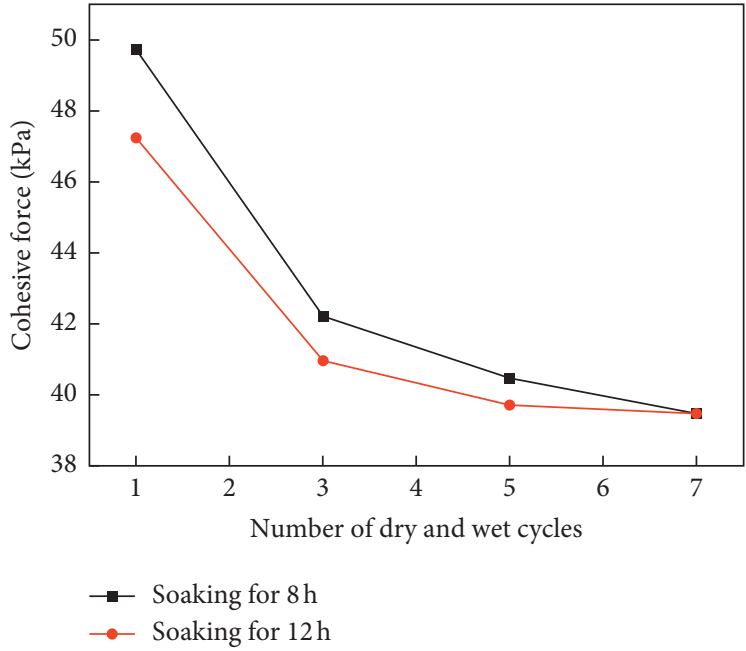

(a)

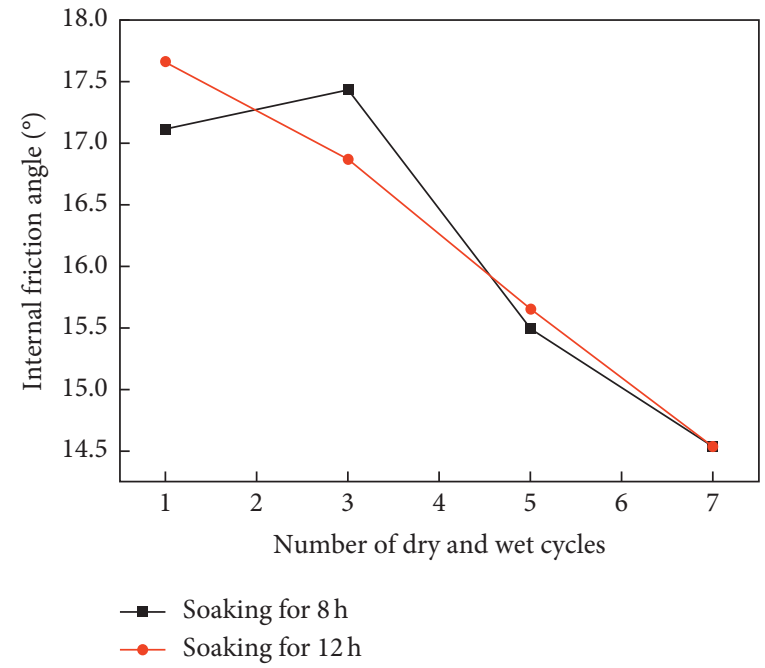

(b)

FIGURE 10: Relationship between $c$ and $\varphi$ parameters and different dry and wet cycles $(8 \mathrm{~h}$ and $12 \mathrm{~h})$.

TABLE 5: Shear strength parameters under different dry and wet cycles.

\begin{tabular}{lccccc}
\hline Cycles & \multicolumn{2}{c}{ Cohesive force $(\mathrm{kPa})(4 \mathrm{~h}, 8 \mathrm{~h}$, and $12 \mathrm{~h})$} & \multicolumn{2}{c}{ Angle of internal friction $\left(^{\circ}\right)(4 \mathrm{~h}, 8 \mathrm{~h}$, and $12 \mathrm{~h})$} \\
\hline 1 & 51.84 & 49.73 & 47.228 & 18.13 & 17.114 \\
2 & 48.67 & - & - & 16.92 & - \\
3 & 45.42 & 42.194 & 40.957 & 16.41 & 17.432 \\
5 & 43.35 & 40.449 & 39.703 & 15.28 & 15.488 \\
7 & 42.76 & 39.466 & 39.576 & 14.6 & 14.537 \\
9 & 42.43 & - & - & 13.94 & - \\
\hline
\end{tabular}

confining pressure. The maximum deviatoric stress was $645.7125 \mathrm{kPa}$, and the minimum was $492.928 \mathrm{kPa}$ under a $300 \mathrm{kPa}$ confining pressure.

The relationship curve of cohesion and internal friction angle of red clay with the number of drying-wetting cycles under the condition of consolidation drainage test was drawn, as shown in Figure 14.

As seen in Figure 14, under the conditions of triaxial consolidation and the drainage test, the attenuation law of cohesion and the internal friction angle of red clay were 


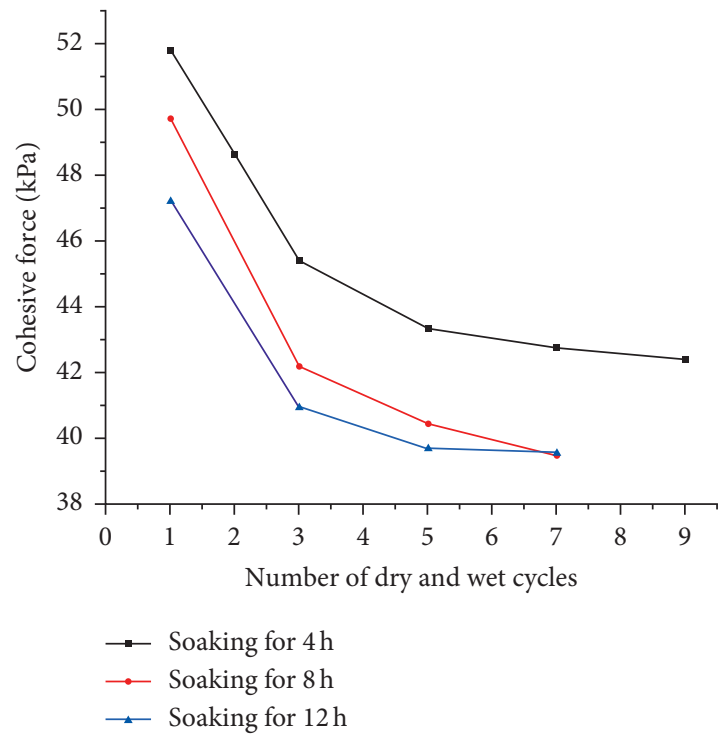

(a)

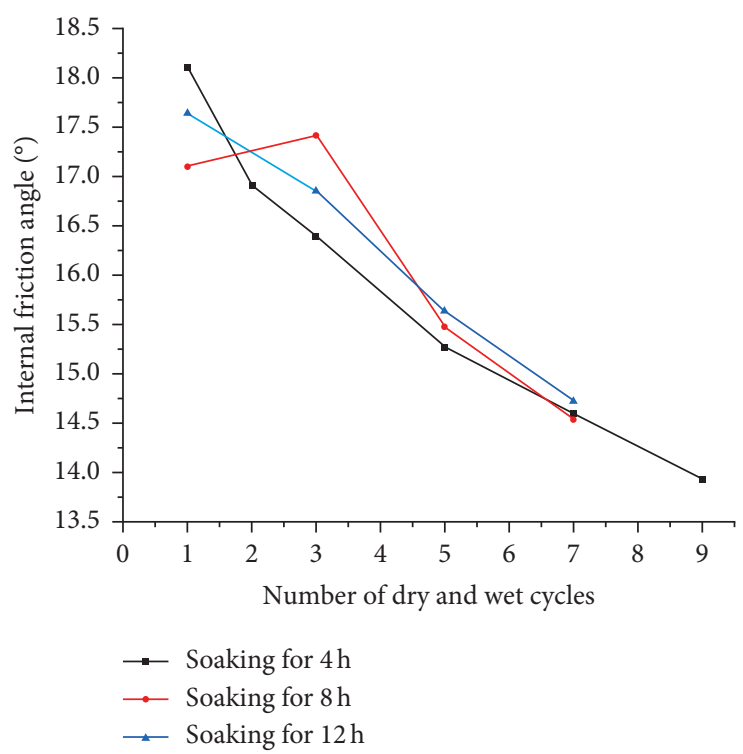

(b)

Figure 11: Relationship between $c$ and $\varphi$ parameters and different dry and wet cycles $(4 \mathrm{~h}, 8 \mathrm{~h}$, and $12 \mathrm{~h})$.

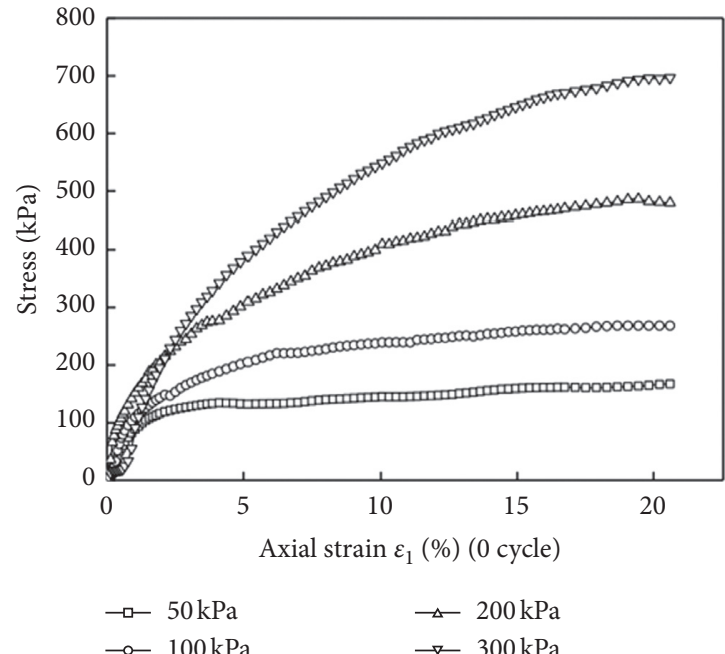

(a)

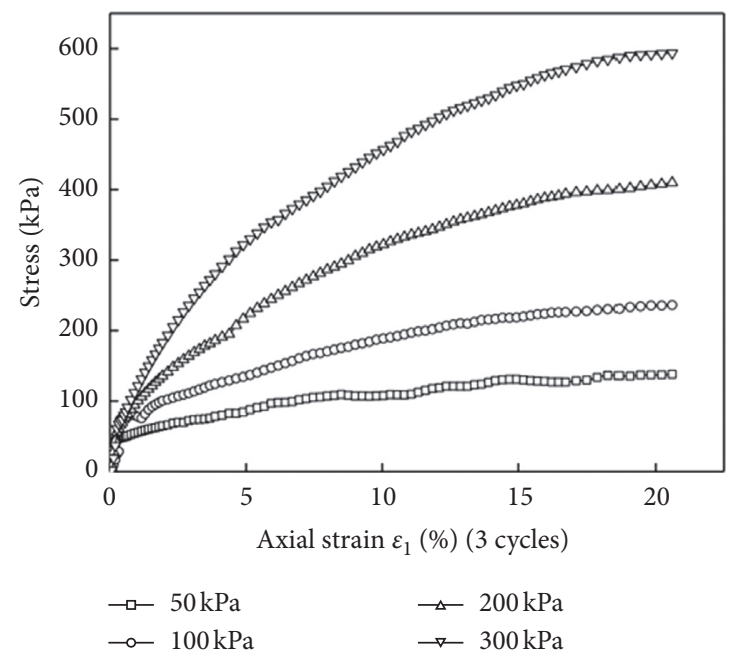

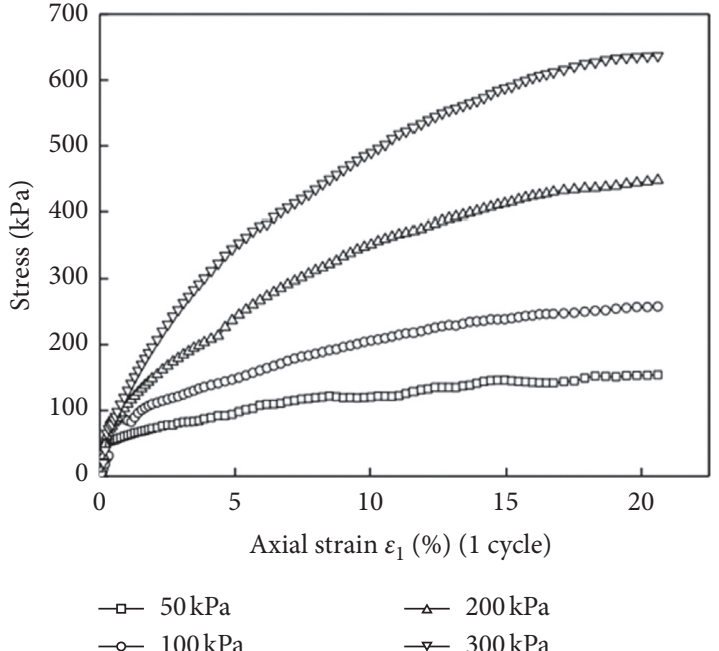

(b)

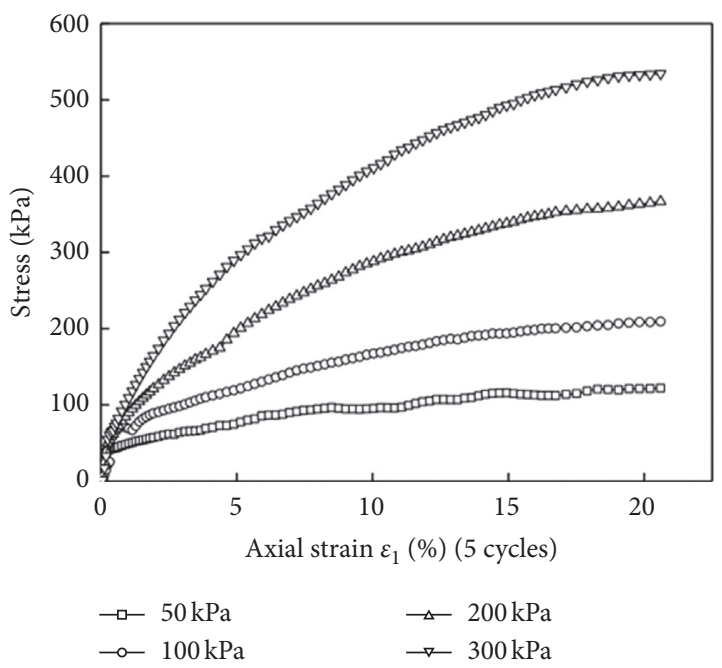

(d)

Figure 12: Continued. 


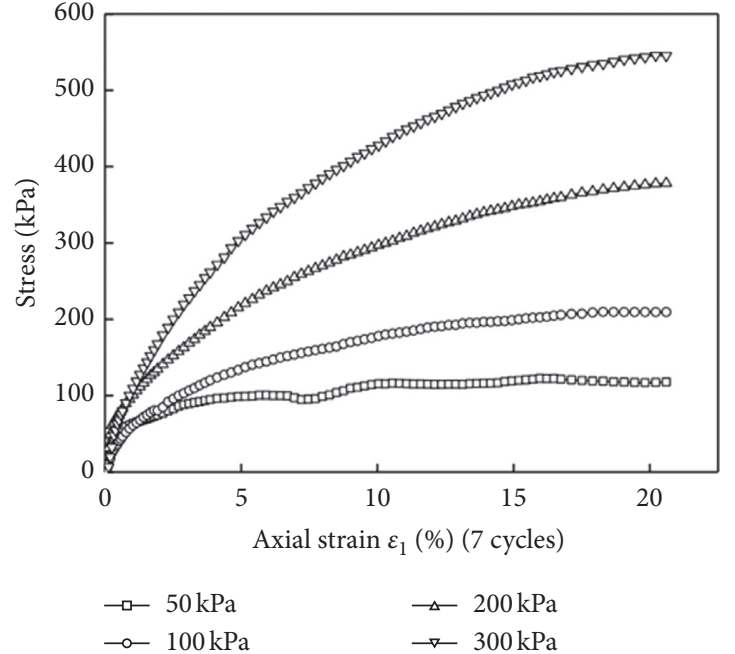

(e)

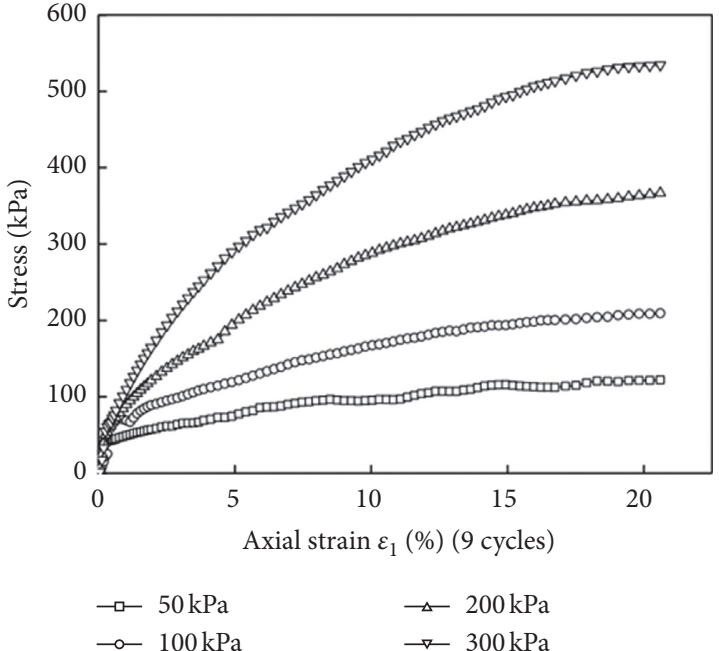

(f)

Figure 12: Deviatoric stress-axial strain relation curve of red clay under different wet and dry cycles.

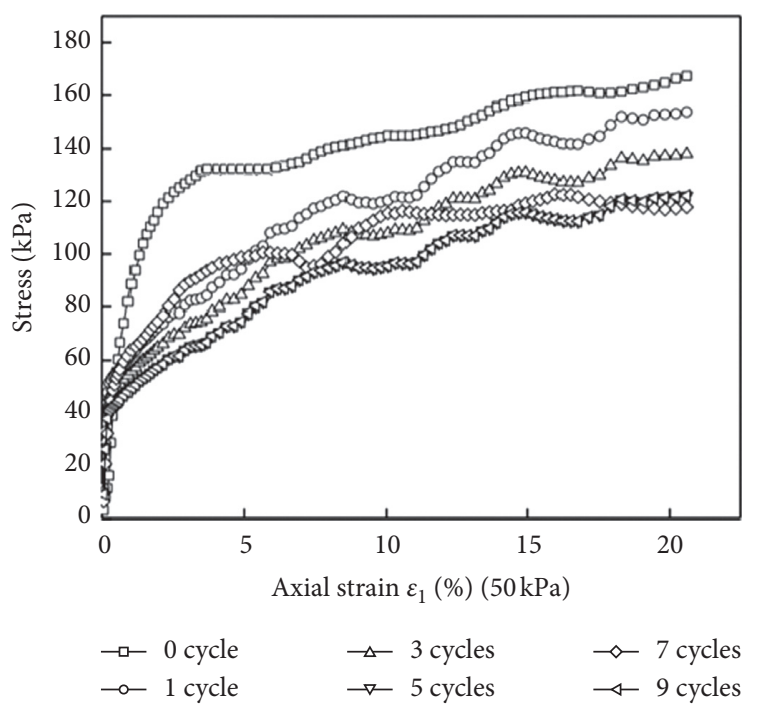

(a)

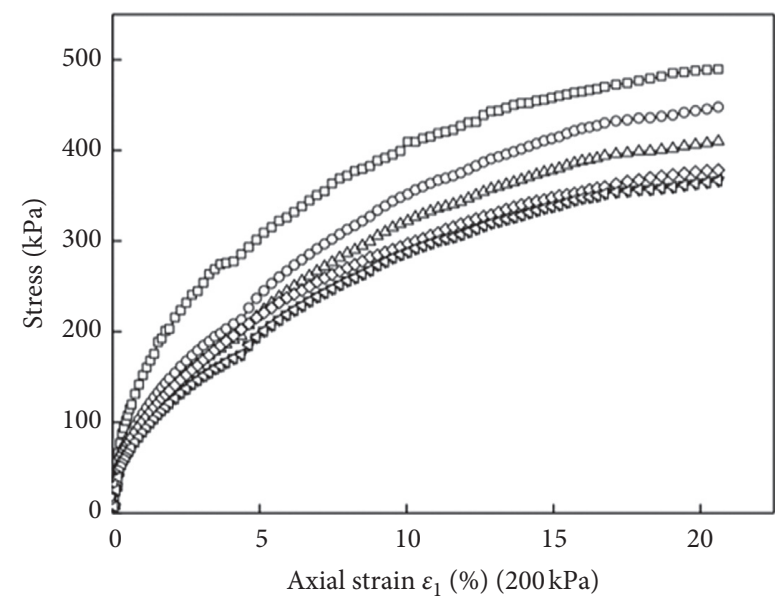

$\begin{array}{lll}\rightarrow 0 \text { cycle } & -3 \text { cycles } & \checkmark 7 \text { cycles } \\ \multimap-1 \text { cycle } & \rightarrow 5 \text { cycles } & -9 \text { cycles }\end{array}$

(c)

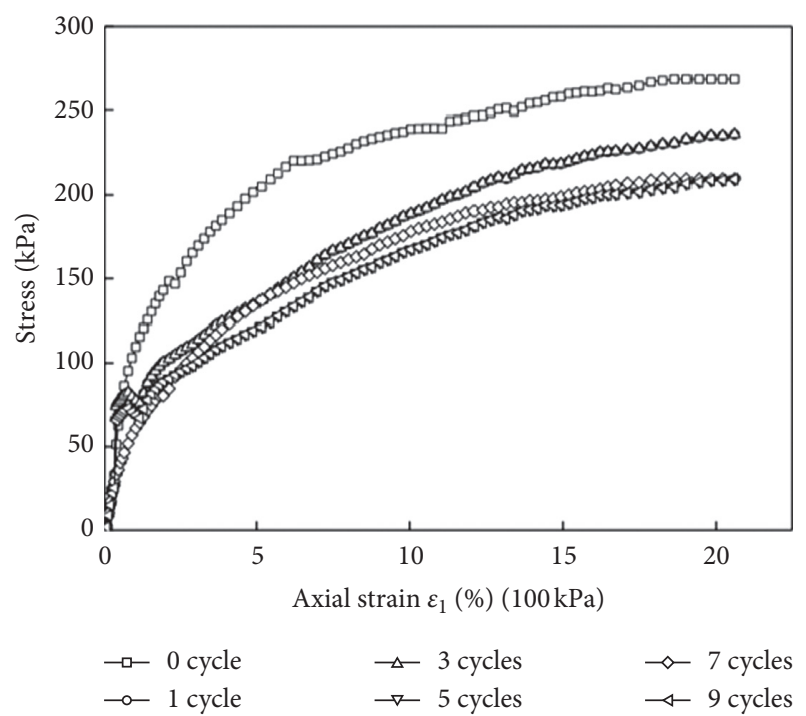

(b)

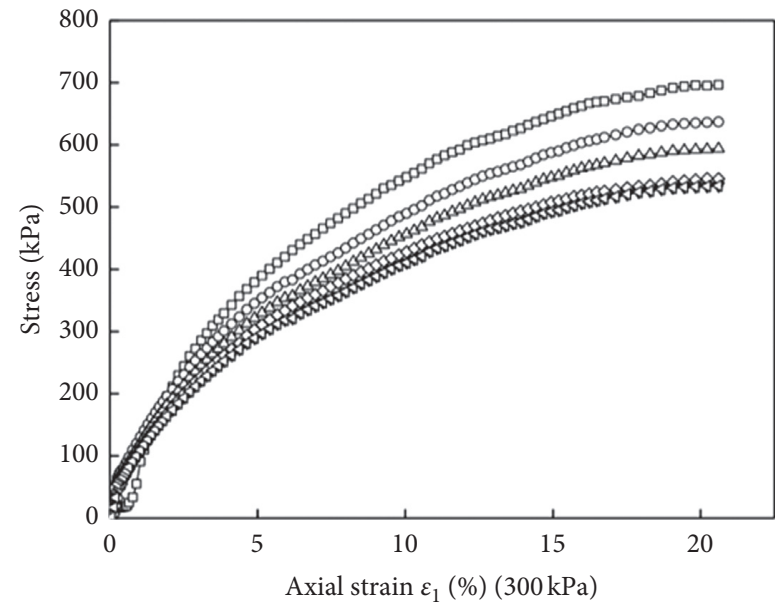

$$
\begin{array}{lll}
\rightarrow 0 \text { cycle } & -3 \text { cycles } & \checkmark 7 \text { cycles } \\
\multimap-1 \text { cycle } & \rightarrow 5 \text { cycles } & -9 \text { cycles }
\end{array}
$$

(d)

Figure 13: Deviatoric stress curve of dry and wet red clay under same confining pressure. 


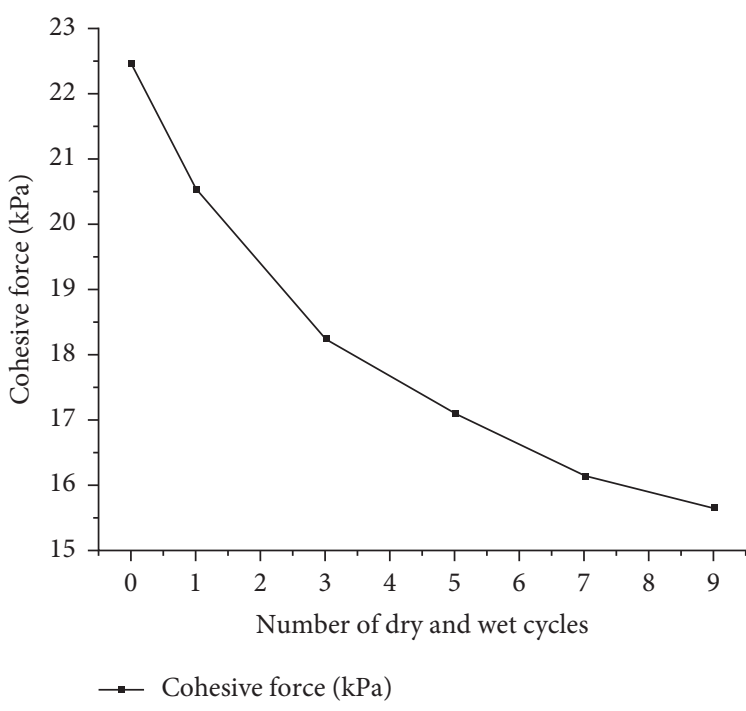

(a)

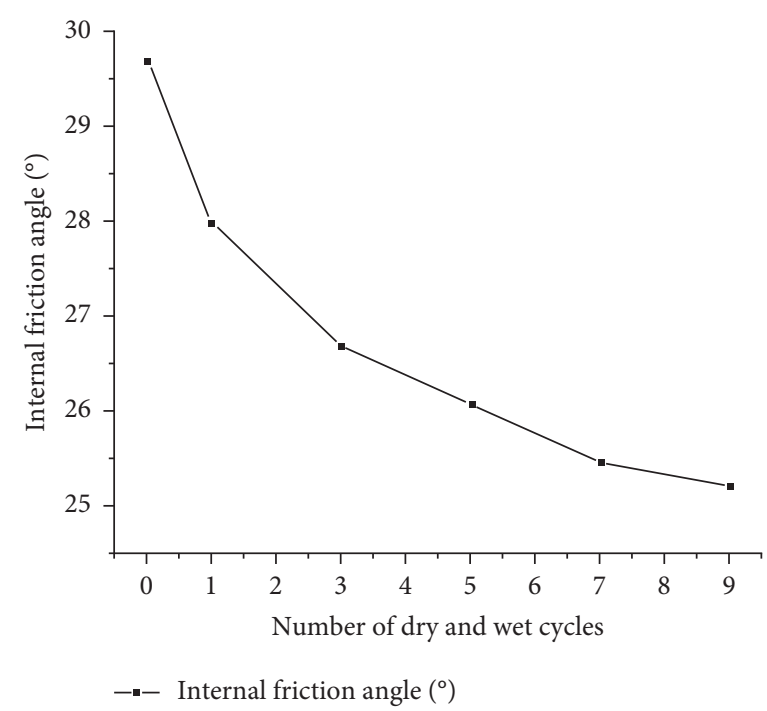

(b)

FIGURE 14: Relationship between $c$ and $\varphi$ parameters and different dry and wet cycles.

similar, and both decreased with an increase in the number of drying-wetting cycles.

3.3. Constitutive Analysis. The plastic hardening (P-H) model is a shear and volume hardening constitutive model that simulates the mechanical behavior of soil. When subjected to biased loads (e.g., in conventional triaxial drainage tests), the soil generally exhibits reduced stiffness with irreversible deformation. In most cases, the deviatoric stress and axial strain curves obtained in drainage triaxial tests can be approximated to hyperbolic curves. Duncan-Chang (1970) discussed this feature in his famous hyperbolic model of soil, expressed using a nonlinear elastic model. The P-H model was established within a hardened plastic framework [19], which eliminated the main defects of the original nonlinear elastic model (such as the monitoring of loading/ unloading modes and the volume modulus lacking specific physical significance).

According to the results of the above tests, the vertical stress is taken as the abscissor, the shear stress is taken as the ordinate to draw the molar stress circle at the time of failure, and the Coulomb strength line is fitted. The results of $0,1,3$, 5, 7, and 9 cycles were obtained, as shown in Figure 15. According to the fitting results, the triaxial shear strength parameters $c_{\mathrm{d}}$ and $\varphi_{\mathrm{d}}$ of red clay under the drying-wetting cycle are shown in Table 6 . It can be seen from the table that the effective cohesion and effective internal friction angle of red clay are reduced due to the drying-wetting cycle. Among them, the first drying-wetting cycle cohesion decreased significantly by $8.71 \%$, the last gradually decreased by $15.65 \mathrm{kPa}$, and the internal friction angle decreased by $4.48^{\circ}$ cumulatively.

To study the attenuation law of the strength parameters of red clay under the action of a drying-wetting cycle, Origin was used for nonlinear fitting, and the fitting results are shown in Figure 16.
Equations (1) and (2) were obtained by fitting and reflect the relationship between the cohesive force and internal friction angle of drying-wetting cycle red clay and the number of drying-wetting cycles. This indicates that the $\mathrm{P}-\mathrm{H}$ model is applicable to the strength and deformation analysis of red clay.

$$
\begin{aligned}
& c=25.31394-5.18286 n 0.28667\left(R^{2}=0.99857\right), \\
& \phi=34.91666-6.93522 n 0.15483\left(R^{2}=0.99736\right) .
\end{aligned}
$$

3.4. Microstructure Analysis. The microscopic mechanism and structural characteristics of dry and wet red clay were studied. Scanning electron microscopy (SEM) was used to scan the samples with different cycles of drying and wetting, and microstructure images with different magnifications were collected. The results of the images were qualitatively analyzed, and three microstructural parameters (directional frequency, equivalent diameter, and abundance) were selected for quantitative statistical analysis using IPP software. The conclusions are as follows:

(1) By analyzing the microscopic images of natural red clay and remolded red clay, it can be seen that the natural red clay particles often form aggregates under the action of cementing materials and minerals, and the porosity is high. Remolded soil destroys the bonding effect of red clay aggregates, the content of small particles is high, and the distribution of small particles is uniform. Under the action of wetting and drying cycles, the large granules of the red clay were further destroyed, the granules showed a tendency of directional arrangement, and the pores increased somewhat, as shown in Figure 17.

(2) The drying-wetting cycle increases the pore size of the red clay sample, and the soil structure is greatly 


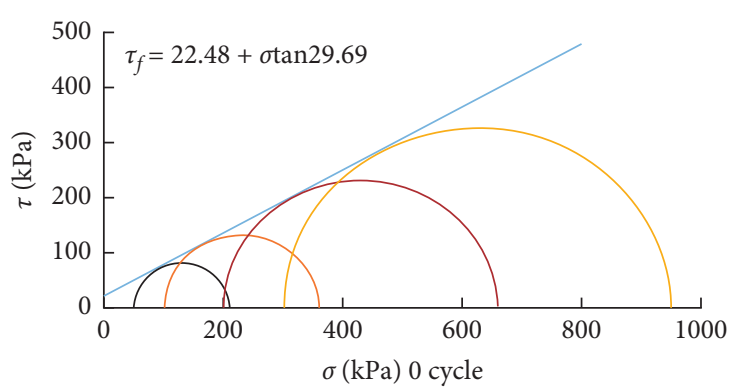

(a)

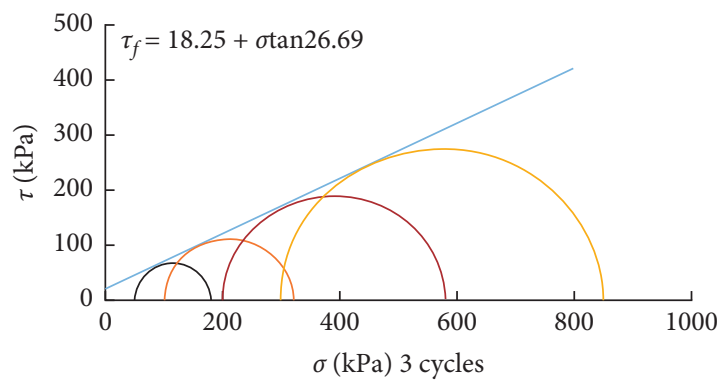

(c)

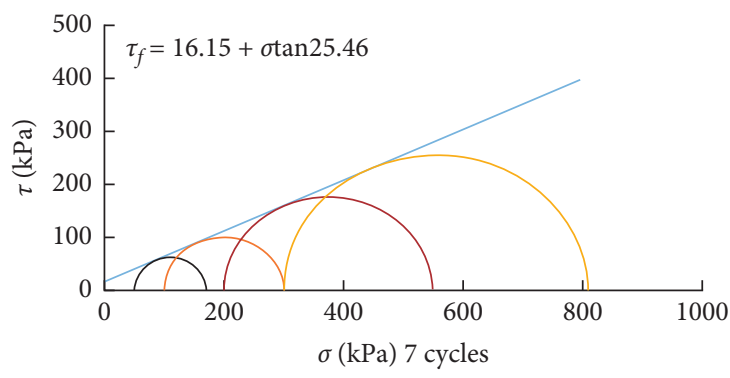

(e)

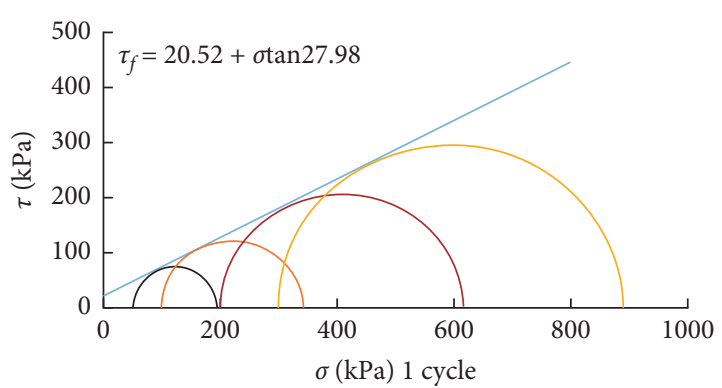

(b)

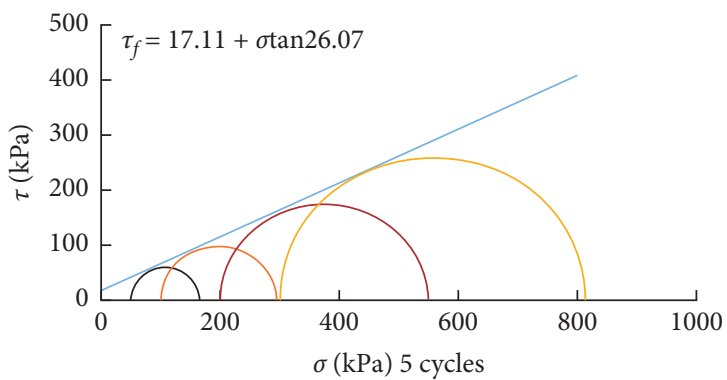

(d)

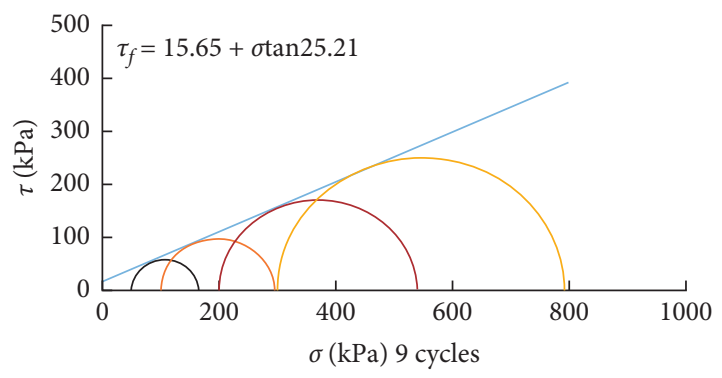

(f)

Figure 15: Molar stress circles and Coulombic strength lines of red clay failure under different wet and dry cycles $\left(\tau_{f}=c_{d}+\sigma \tan \varphi_{\mathrm{d}}\right)$.

TABLE 6: Strength parameters of red clay under different wet and dry cycles.

\begin{tabular}{lcccccc}
\hline Number of dry and wet cycles & 0 & 1 & 3 & 5 & 7 & 9 \\
\hline Cohesive force, $c_{\mathrm{d}}(\mathrm{kPa})$ & 22.48 & 20.52 & 18.25 & 17.11 & 16.15 \\
Angle of internal friction, $\varphi_{\mathrm{d}}\left({ }^{\circ}\right)$ & 29.69 & 27.98 & 26.69 & 26.07 & 25.46 & 25.21 \\
\hline
\end{tabular}

damaged. After the drying-wetting cycle, there were holes on the surface of the red clay sample, and traces of water flow were obvious. An analysis of the increase in the content of small particles suggests that the drying-wetting cycle makes the surface of the particles round, while the large soil particles develop and disintegrate. Meanwhile, the water osmotic effect makes the particle arrangement tend to be in the same direction, as shown in Figure 18.

(3) For the samples under triaxial compression, the characteristics of particles and pores were different in the vertical and horizontal planes. In the horizontal plane, the particles were evenly distributed, the sample surface was smooth, and the pores did not change significantly. In the vertical plane, the particles were tightly arranged and directional. The particles were compacted and partially cemented to form an overall aggregate and the number of pores decreased, as shown in Figure 19.

(4) Through a quantitative analysis of the particles and pores of red clay with drying-wetting cycles by digital image processing technology, it is found that the drying-wetting cycle has an effect on the geometric characteristics and spatial morphological characteristics of the particles and pores. In the initial state, the arrangement of particles and pore space is anisotropic. After several cycles of drying and wetting, the particles have an obvious orientation. The 


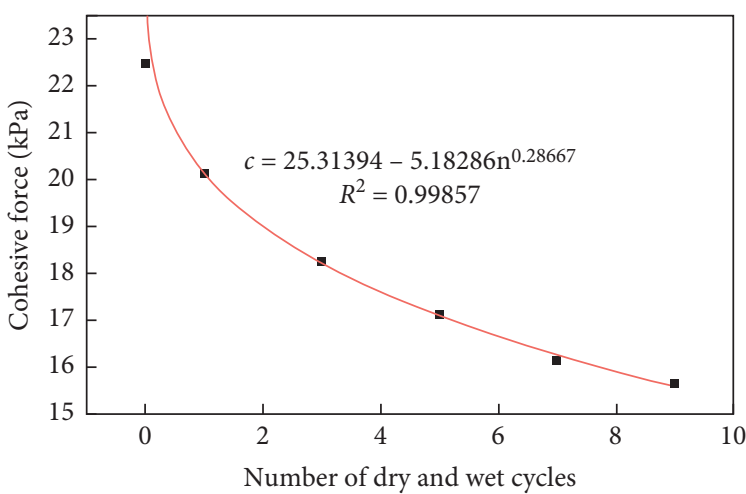

- Cohesive force $(\mathrm{kPa})$

Fitting curve

(a)

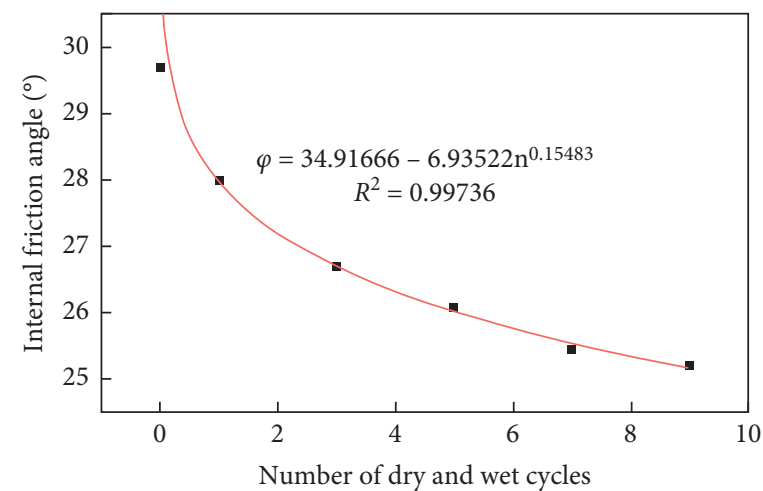

- Internal friction angle $\left(^{\circ}\right)$

Fitting curve

Figure 16: Fitting result between $c$ and $\varphi$ and number of dry and wet cycles.

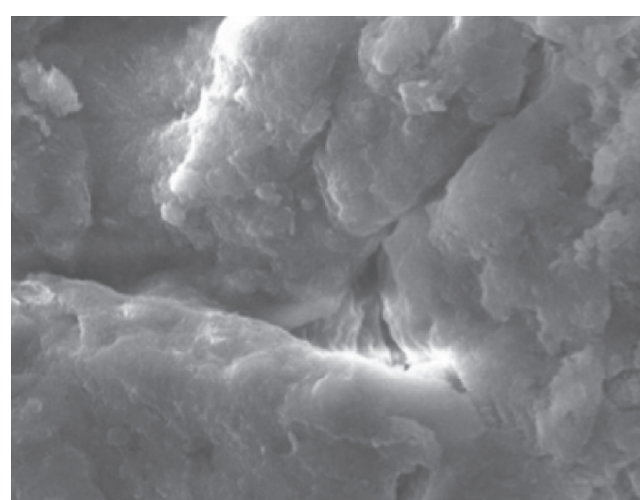

(a)

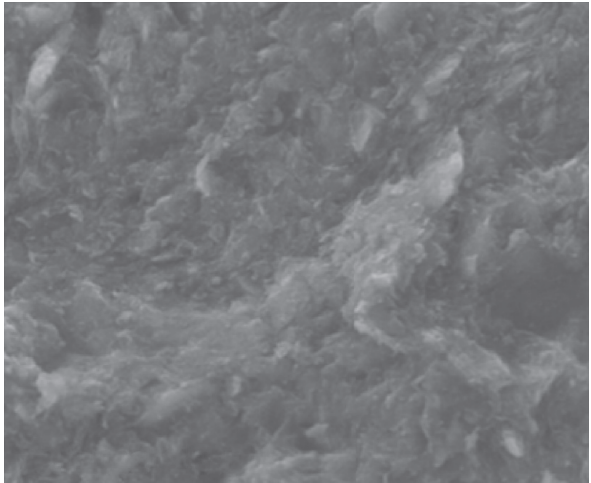

(b)

FIgURE 17: Microscopic images of natural and remolded red clay at 2000× magnification. (a) Natural state. (b) Reshape state.

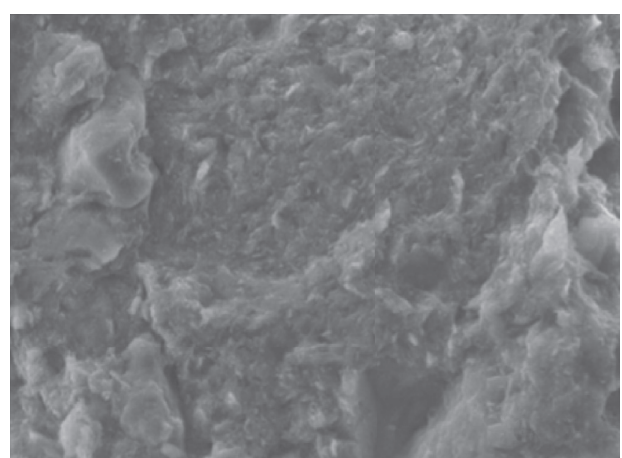

(a)

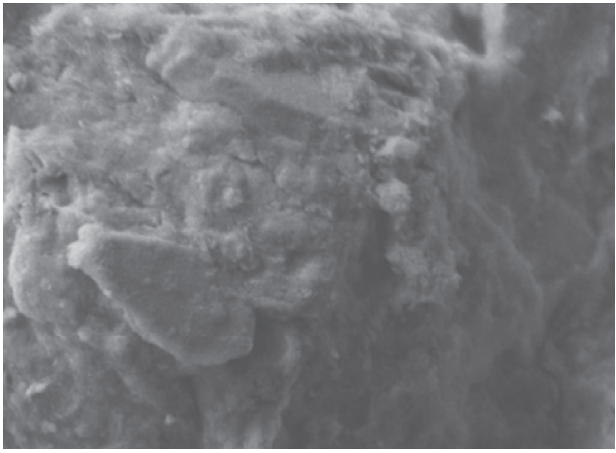

(c)

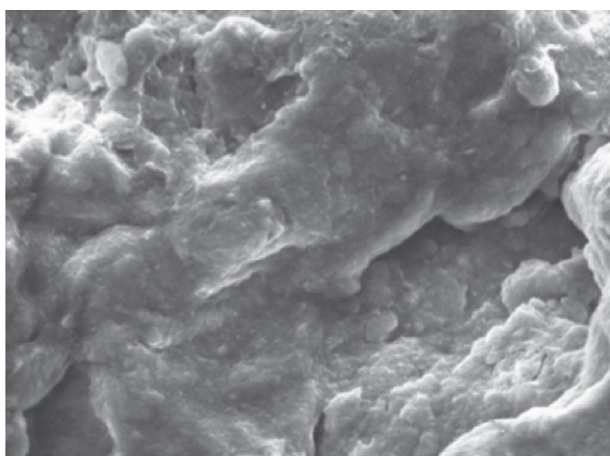

(b)

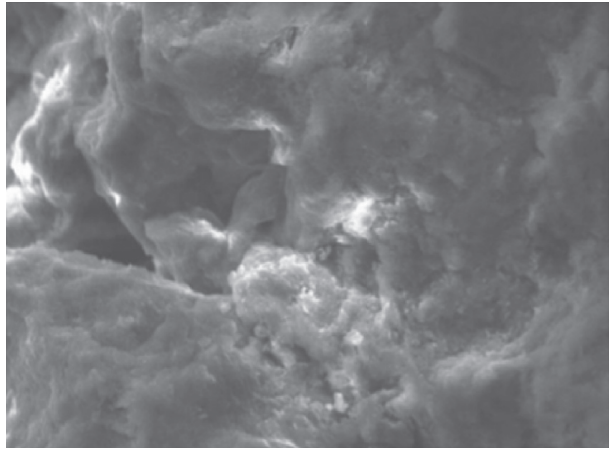

(d)

Figure 18: Microcosmic images of red clay at 1000× magnification under different wet and dry cycles. (a) 0 cycles. (b) 3 cycles. (c) 5 cycles. (d) 9 cycles. 

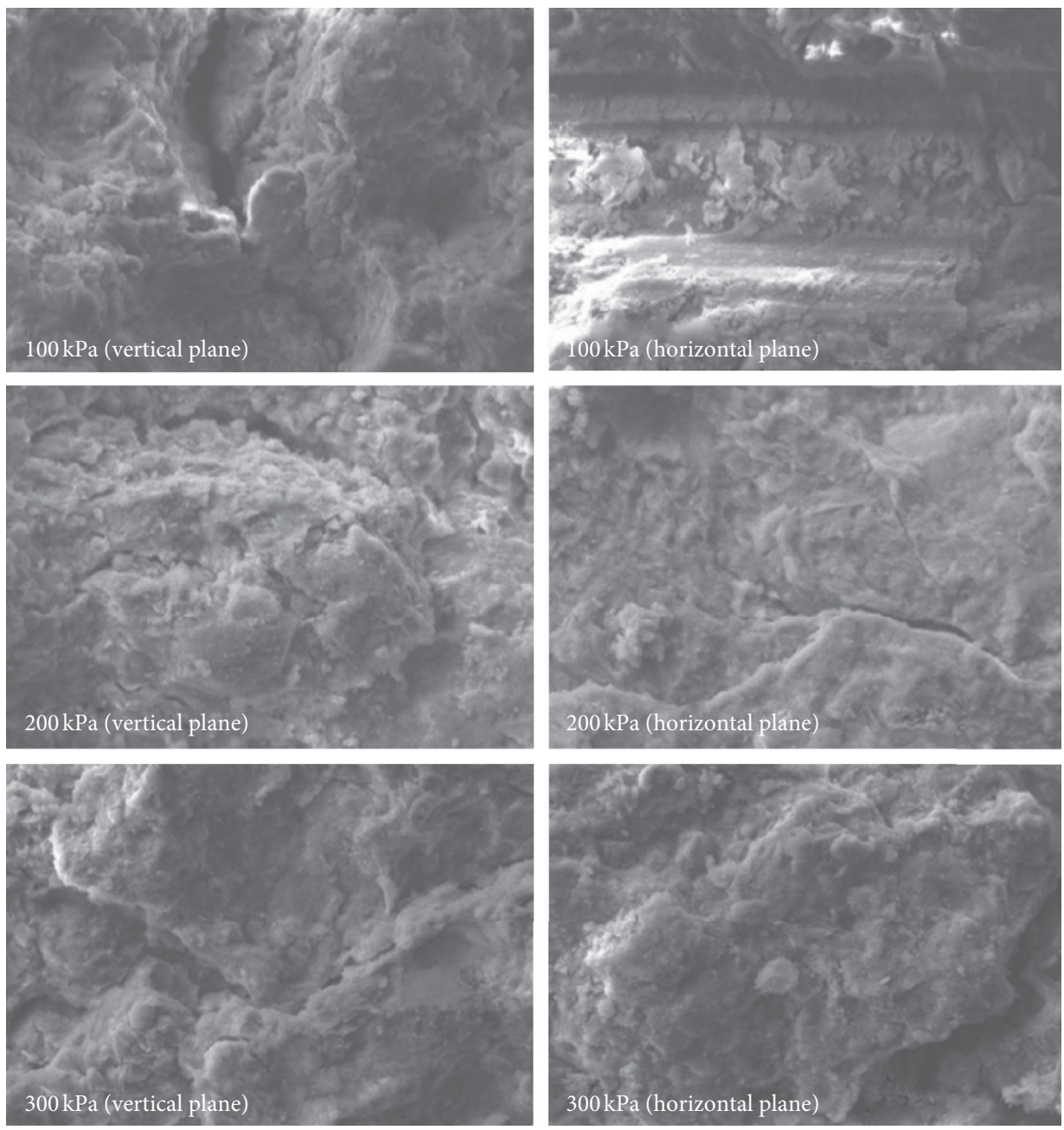

FIgURE 19: Images of triaxial test failure samples of red clay magnified 500× under different confining pressures.

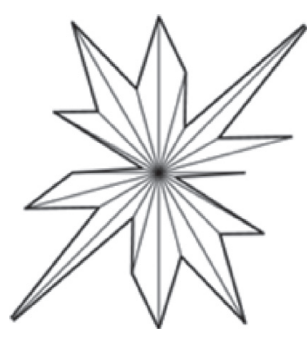

(a)

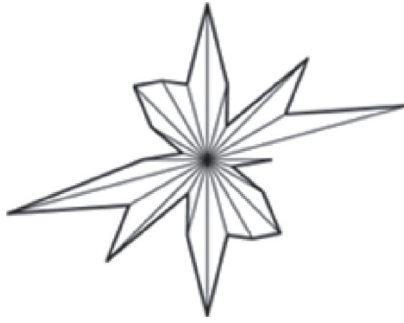

(b)

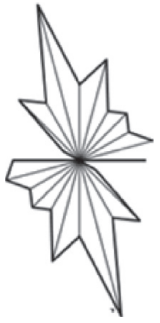

(c)

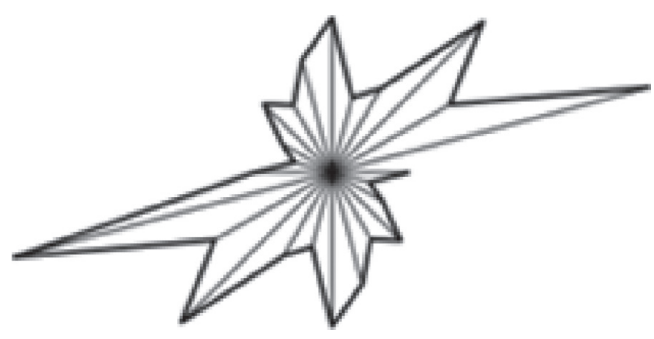

(d)

Figure 20: Roses of oriented arrangement of red clay particles under different wet and dry cycles. (a) 0 cycles. (b) 3 cycles. (c) 6 cycles. (d) 9 cycles.

equivalent diameter of red clay is less than $2 \mu \mathrm{m}$, which has the highest particle size content $(>40 \%)$. After the drying and wetting cycle, the particle size content of $2-10 \mu \mathrm{m}$ increases, and the particle size of larger than $10 \mu \mathrm{m}$ decreases, as shown in Figures 20 and 21. In terms of particle shape, the red clay is mainly ellipsoidal. Under the drying-wetting cycle, the percentage of red clay abundance increases from $0.4 \mu \mathrm{m}$ to $0.7 \mu \mathrm{m}$. In terms of porosity, the red clay has similar characteristics, as shown in Figure 22. 


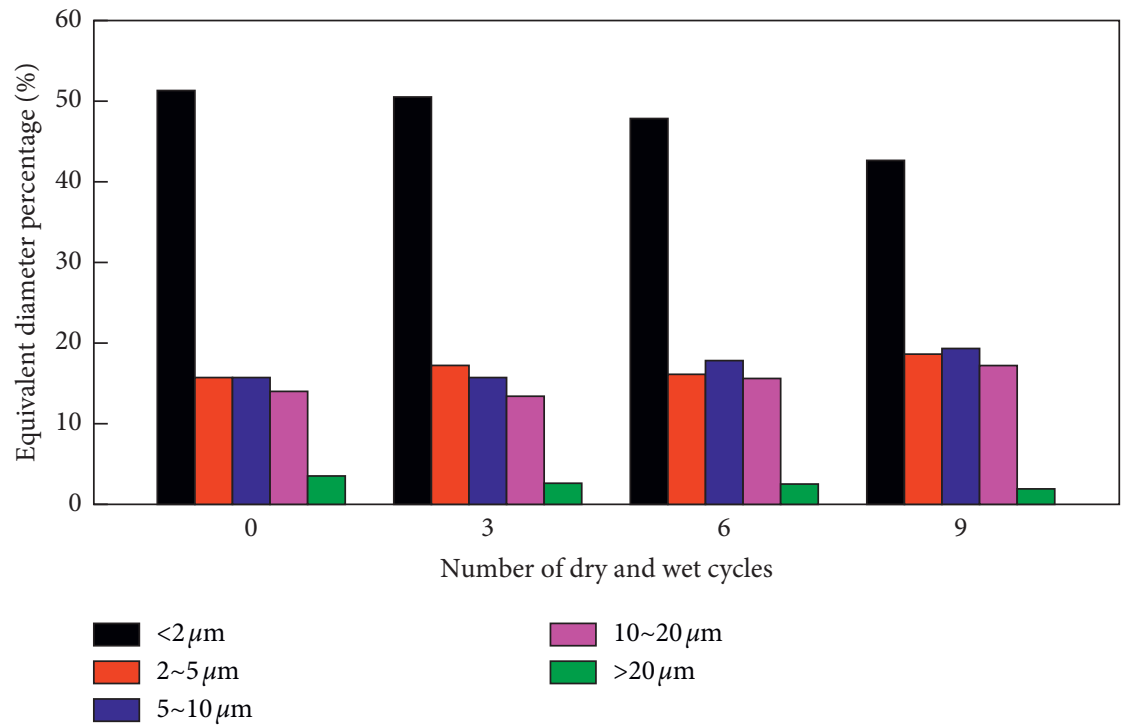

FIgURE 21: Equivalent diameter percentage distribution of soil particles under different drying-wetting cycles.

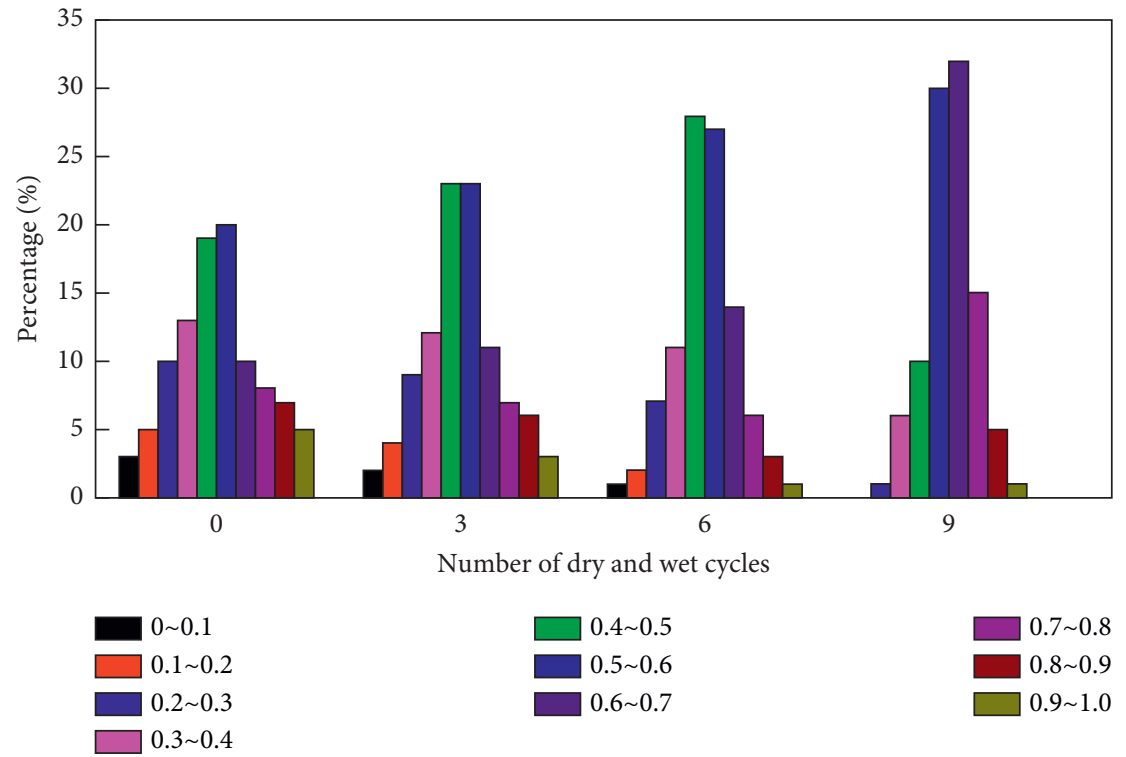

FIGURE 22: Abundance percentage distribution of soil particles under different drying-wetting cycles.

\section{Conclusions and Discussion}

(1) Regardless of the direct shear test or triaxial test, the shear strength parameters of red clay decrease with an increase in the number of cycles and the attenuation is the most obvious in the first cycle process and gradually decreases with an increase in the number of cycles.

(2) The direct shear tests under wetting and drying cycles showed that the shear strength of red clay decreases with an increase in the number of cycles, which is nonlinear. After several cycles, the strength parameters of red clay tend to stabilize. The direct shear test results of the dry red clay under wetting and drying cycles showed that the strength of the dry red clay is dispersed to a certain extent, and the shear surface is not smooth. Rather, it is a concave and convex surface. The analysis indicated that this is caused by the weak structural surface produced by the dry shrinkage and the uneven bonding strength.

(3) Under the drying-wetting circulation red clay partial stress and axial strain curve for the plastic hardening model, the maximum deviatoric stress under different confining pressure decreases with an increase in the number of drying-wetting circulations. The first drying-wetting circulation decline was the greatest. With an increase in the number of dry and wet cycles, the attenuation gradually decreased. 
According to the analysis, the structure of red clay is destroyed by the drying-wetting circulation due to the swelling and shrinkage of red clay.

(4) By analyzing the variation of parameters in the P-H model, the relationship between the mechanical parameters of red clay and the number of dryingwetting cycles was obtained, including the relationship between $c, \varphi$, and the number of cycles $n$. The results showed that the parameters attenuated to different degrees with the action of drying-wetting cycles. In addition, it was shown that the P-H model is applicable to the strength and deformation analysis of red clay.

(5) Qualitative analysis and quantitative analysis were used to analyze the microstructure of red clay. The microscopic image qualitative analysis results verified the macroscopic mechanical characteristics of red clay (1)-(4). The microstructural parameters of directional frequency, equivalent diameter, and abundance were quantitatively analyzed, and the analysis results explained the mechanical characteristics of red clay from the microcosmic perspective.

(6) Most of the current research simulates the dryingwetting cycle after the sample is made, that is, to predry and wet to a certain number of cycles out of the stress state and then apply the load. This operation obviously fails to consider both load and drying-wetting cycles, amplifying the effect of drying-wetting cycles on red clay, which is different from the actual situation [20]. These deficiencies need to be considered in subsequent studies.

\section{Data Availability}

The data used to support the findings of this study are available from the corresponding author upon request.

\section{Conflicts of Interest}

The authors declare that they have no conflicts of interest.

\section{Acknowledgments}

This work was supported by the National Key Research and Development Project of China, the Ministry of Science and Technology of China (Grant 2018YFC1505504), and the National Natural Science Foundation of China (NSFC) (41272339)

\section{References}

[1] H. E. Yi-Dong, Several Studies on Red Clay, Guangxi University, Guangxi, China, 2007.

[2] L.-W. Kong and Z. Chen, "Advencement in the techniques for special soils and slopes," China Civil Engineering Journal, vol. 45, no. 5, pp. 141-161, 2012.
[3] Y. Cheng, C. Wei, and N. I. U. Geng, "Influence of dryingwetting cycle on shear strength of red clay in karst area," Rock and Soil Mechanics, vol. 38, no. 2, pp. 191-196, 2017.

[4] H. B. Lü, Z. T. Zeng, Y. L. Zhao, and H. Lu, "Experimental studies of strength of expansive soil in drying and wetting cycle," Rock and Soil Mechanics, vol. 30, no. 12, pp. 37973802, 2009.

[5] F. Z. Zhang and X. P. Chen, "Influence of repeated drying and wetting cycles on mechanical behaviors of unsaturated soil," Chinese Journal of Geotechnical Engineering, vol. 32, no. 1, pp. 41-46, 2010.

[6] T Y. Zhi, L. W. Kong, A. G Guo, and X. Feng, "Discussion on the compaction degree index of subgrade filled with laterite," Rock and Soil Mechanics, vol. 31, no. 3, pp. 851-855, 2010.

[7] H.-P. Yang, X.-Z. Wang, and J. Xiao, "Influence of wettingdrying cycles on strength characteristics of Nanning expansive soils," Chinese Journal of Geotechnical Engineering, vol. 36, no. 5, pp. 949-954, 2014.

[8] H.-P. Yang, R. Zhang, and J.-L. Zheng, "Variation of deformation and strength of expansive soil during cyclic wetting and drying under loading condition," Chinese Journal of Geotechnical Engineering, vol. 28, no. 11, pp. 1936-1941, 2006.

[9] L.-W. Kong, J.-B. Chen, A.-G. Guo, and Y.-L. Zhao, "Field response test on expansive soil slopes under atmosphere," Chinese Journal of Geotechnical Engineering, vol. 29, no. 7, pp. 1065-1073, 2007.

[10] D.-A. Sun and D.-J. Huang, "Soil-water and deformation characteristics of Nanyang expansive soil after wetting-drying cycles," Rock and Soil Mechanics, vol. 36, no. 1, pp. 115-119, 2015.

[11] Q. Yang, J. He, and M.-T. Luan, "Comparative study on shear strength of unsaturated red clay and expansive soil," Rock and Soil Mechanics, vol. 24, no. 1, pp. 13-16, 2003.

[12] K. S. Chen, "Shrinkage deformation characteristics of compacted red clay," Highway, vol. 60, no. 2, pp. 25-29, 2015.

[13] K. S. Chen, "Study of shear strength characteristics for red clay under wet and dry cycles," Highway, vol. 61, no. 2, pp. 45-49, 2016.

[14] K. Mu, L. Kong, X. Zhang, and S. Yin, "Experimental study on drying-wetting cycle effect of engineering properties of red clay," Rock and Soil Mechanics, vol. 37, no. 8, pp. 2247-2253, 2016.

[15] L.-R. Tan and L.-W. Kong, "Fundamental property and microstructure model of red clay," Chinese Journal of Geotechnical Engineering, vol. 23, no. 4, pp. 458-462, 2001.

[16] Y.-Z. Tan, L.-W. Kong, and A.-G. Guo, "Pore size evolution of compacted laterite under desiccation shrinkage process effects," Rock and Soil Mechanics, vol. 31, no. 5, pp. 1427-1430, 2010.

[17] Y. Chen, Q. Wang, Y. U. Ming-Yuan, W. U. Zhong-Hu, B. Gao, and J. Dong, "Study on shear strength and microstructure characteristics of alkali contaminated red clay," Chinese Journal of Engineering Geology, vol. 26, no. 5, pp. 1300-1310, 2018.

[18] Nanjing Hydraulic Research Institute, Standard for Soil Test Method, China Planning Publishing House, Beijing, China, 1999.

[19] T. Schanz, P. A. Vermeer, and P. G. Bonnier, "The hardening soil model: formulation and verification," in Beyond 2000 in Computational Geotechnics, CRC Press, Boca Raton, FL, USA, 1999.

[20] G. Zeng, "Experimental study on mechanical properties of Nigerian red clay under drying-wetting cycle," Railway Construction Technology, no. 5, pp. 39-42+65, 2020. 